\title{
El Club Internacional de San José y la cultura ilustrada finisecular
}

\author{
The International Club of San José and fin de siècle's enlightened \\ culture
}

\author{
Leonardo Santamaría Montero \\ Universidad de Costa Rica \\ leonardo.santamaria@ucr.ac.cr
}

Recepción: 15 de febrero de 2018/Aceptación: 26 de abril de 2018

doi: https://doi.org/10.15517/rehmlac.v10i1.32438

Palabras clave

Club Internacional de Costa Rica; historia de la cultura; Costa Rica; siglo XIX; clubes; organización cultural.

Keywords

International Club of Costa Rica; Cultural History; Costa Rica; 19th century; Clubs; Cultural Organizations.

Resumen

El "Club Internacional", luego denominado "Club Internacional de Costa Rica", fue la asociación cultural más importante de la capital durante las últimas dos décadas del siglo XIX. Esta agrupación privada fue creada como un punto de encuentro para los ciudadanos más "ilustres" de la Costa Rica de la época; un lugar donde dedicaban su tiempo al entretenimiento y a los negocios. La presente investigación se propone introducir al objeto de estudio y para ello: se exploran los antecedentes del Club Internacional, se determinan algunos locales del club, se analizan los estatutos de 1884 , se revisa el relato de uno de sus miembros y se estudian dos eventos acontecidos en 1885. Se propone que mediante el estudio sistemático del Club Internacional y de sus actividades, la historia del arte y la historia de la cultura costarricense encontrarán en él un núcleo de la "cultura ilustrada" finisecular.

Abstract

The "International Club", later named "International Club of Costa Rica", was the capital's most important cultural association at the end of the $19^{\text {th }}$ century. This private group was created as a meeting point for the most "enlightened" citizens; a place where they shared their time for entertainment and business purposes. This research is introductory so in this paper: it explores the antecedents of the International Club, identifies its different locations, analyses its 1884 statutes, reviews a testimony of one of its members and studies two events happened at 1885 . We propose that through the systematic study of International Club, and the social activities derived thereof, the Art History and Cultural History of Costa Rica will find in this association an important core of its fin de siècle's "enlightened culture".

\section{Introducción}

El Club Internacional, luego denominado Club Internacional de Costa Rica, fue la asociación civil burguesa más importante de la capital durante las dos últimas décadas del siglo XIX. Esta agrupación privada fue creada, en plena crisis de la masonería costarricense, como un punto de encuentro para los ciudadanos más ilustres de la Costa Rica de la época; un lugar donde los miembros de las élites dedicaban su 
tiempo al entretenimiento y a los negocios. Consecuentemente, desde su fundación hacia 1880, el Club Internacional fue protagonista del escenario sociocultural de la burguesía josefina.

Este trabajo pretende contribuir a la historiografía de la cultura costarricense, principalmente al estudio de los clubes y sus vínculos con (i) la crisis de la masonería en Costa Rica, (ii) el desarrollo de las sociabilidades modernas en ese país y (iii) la formación de la alta cultura josefina a finales del siglo XIX. Debe señalarse que la investigación histórico-cultural no registra trabajos que estén dedicados al examen del Club Internacional. Por ello, la presente investigación tiene por objetivo introducir al estudio del Club Internacional mediante un análisis de su surgimiento, sus estatutos y su impacto social en relación con la cultura ilustrada finisecular y las sociabilidades costarricenses burguesas.

¿Cuáles son las relaciones entre la creación del Club Internacional, la crisis de la masonería costarricense y el auge de las sociabilidades burguesas en la Costa Rica de la década de 1880? Para responder dicha pregunta de investigación se establecieron los siguientes objetivos: (i) vincular al Club Nacional con el Club Internacional, siendo el primero el posible antecedente directo del segundo y a su vez una consecuencia de la crisis experimentada por la masonería costarricense a partir de 1876; (ii) caracterizar al Club Internacional a partir de la determinación de su ubicación geográfica, el estudio de los estatutos de 1884 y la revisión del testimonio de uno de sus miembros; (iii) y analizar la incidencia del Club Internacional en la vida cultural de las élites costarricenses en 1885 .

Para alcanzar el tercer objetivo, se estudian dos proyectos gestados en el Club Internacional en el segundo semestre de 1885: la fundación de la Junta del Teatro y el baile en conmemoración al quinto aniversario del club. Como se verá en este artículo, ambos eventos estuvieron intrínsecamente vinculados con un proyecto cultural que articulaba ideas ilustradas, progresistas y nacionalistas. Así, el Club Internacional funcionó como un espacio de sociabilidad y a la vez como una herramienta de la comunidad de ciudadanos ilustrados, quienes legitimaron su elevado estatus social y pretendieron potenciar el progreso cultural de la ciudad de San José y de la República de Costa Rica.

Para desarrollar este artículo se consultaron fuentes primarias resguardadas por la Biblioteca Nacional de Costa Rica. La mayor parte de los documentos consultados son periódicos, pues la historiografía de las últimas dos décadas ha demostrado la correlación que existió en Latinoamérica entre la prensa, la formación de una opinión pública urbana y el auge de las sociabilidades modernas a lo largo del siglo XIX ${ }^{1}$. Los

\footnotetext{
${ }^{1}$ Gilberto Loaiza Cano, "Hombres de sociedades (masonería y sociabilidad político-intelectual en Colombia e Hispanoamérica durante la segunda mitad del siglo XIX)", Revista Historia y Espacio, no. 17 (2001): 93-130. Pilar González Bernaldo de Quirós, "Sociabilidad y opinión pública en Buenos Aires (1821-1852)", Historia Contemporánea, no. 27 (2003): 663-694. González, "Literatura injuriosa y opinión pública en Santiago de Chile durante la primera mitad del siglo XIX”, Estudios Públicos, no. 76 (1999): 233-262. Ricardo Martínez Esquivel, Masones y masonería en la Costa Rica de los albores de la modernidad (1865-1899) (San José, EUCR, 2017).
} 
documentos son analizados a la luz de las ideas y las sociabilidades de los individuos o grupos asociados con su publicación, lo cual permite caracterizar el campo cultural examinado y realizar, hasta donde las fuentes lo permitan, una interpretación sociológica de lo acontecido en torno al Club Internacional ${ }^{2}$. Las teorías y los métodos señalados se subsumieron bajo el meta-método conocido como "hipotético deductivo" y mediante la "falsación metodológica" se llegó al grupo de hipótesis con mayor fecundidad explicativa y mayor contenido empírico corroborado ${ }^{3}$.

\section{El Club Nacional, la crisis de la masonería costarricense y las sociabilidades burguesas finiseculares}

Posterior a la fundación de la República de Costa Rica (1848) y en el marco de la incorporación del país al mercado mundial, la ciudad de San José inició la transformación del paisaje y experimentó una diversificación de los servicios, los entretenimientos urbanos y las sociabilidades modernas ${ }^{4}$. Como parte de dicha modernización urbana y en respuesta a la creciente visita de extranjeros, en San José se establecieron hoteles, restaurantes y posadas, entre ellos el "Hotel de Costa-Rica". En el mismo local del hotel funcionó durante la década de 1850 el "Club Nacional" (un club a la inglesa) ${ }^{6}$, donde los hombres de la ciudad podían leer periódicos europeos y disfrutar de juegos de $\operatorname{azar}^{7}$. El club fue administrado por el inglés T. H. H. Cauty, quien probablemente lo fundó con el objetivo de ofrecerles entretenimientos a los visitantes extranjeros y a los miembros de la élite económica josefina, estos últimos vinculados comercialmente con la cultura inglesa ${ }^{8}$. Cauty continuó con ese negocio en el siguiente decenio, pues en 1861 fue publicado el siguiente aviso en el periódico Nueva Era:

\footnotetext{
${ }^{2}$ Pierre Bourdieu, El sentido social del gusto. Elementos para una sociología de la cultura (Buenos Aires: Siglo Veintiuno Editores, 2010). González Bernaldo de Quirós, "La 'sociabilidad' y la historia política”, Nuevo Mundo Mundos Nuevos (2008), http://journals.openedition.org/nuevomundo/24082

${ }^{3}$ Leonardo Santamaría Montero, "Análisis de la conformación del diseño arquitectónico y ornamental del Teatro Nacional de Costa Rica" (Tesis de licenciatura en historia del arte, Universidad de Costa Rica, 2017), 29-30.

${ }^{4}$ Patricia Fumero Vargas, "La Ciudad en la Aldea. Actividades y Diversiones Urbanas en San José de Mediados del Siglo XIX", en Héroes al gusto y libros de moda: sociedad y cambio cultural en Costa Rica 1750-1900, eds. Iván Molina Jiménez y Steven Palmer (San José: Editorial Porvenir, 2004), 77-104. Martínez, Masones y masonería, 48-53. Santamaría, “Análisis de la conformación”, 214-219.

${ }^{5}$ Fumero, "La Ciudad en la Aldea", 82-83.

${ }^{6}$ Los clubes ingleses fueron muy importantes en el siglo XIX como espacio de sociabilidad y para conferirle un estatus social superior a los miembros de las élites. Amy Milne-Smith, London Clubland: A Cultural History of Gender and Class in Late Victorian Britain (Nueva York: Springer, 2011). Antonia Taddei, "London Clubs in the Late Nineteenth Century", Discussion Papers in Economic and Social History (1999).

${ }^{7}$ Adolfo Blen, Historia del periodismo (San José: Editorial Costa Rica, 1983), 77. Fumero, "La Ciudad en la Aldea", 83.

${ }^{8}$ Carmen María Fallas Santana, Elite, negocios y politica en Costa Rica: 1849-1859 (Alajuela: Museo Histórico Juan Santamaría, 2004). Rodrigo Quesada Monge, Recuerdos del imperio: los ingleses en América Central (1821-1915) (Heredia: EUNA, 1998).
} 


\section{CLUB DE LA UNION.}

El crecido número de extrangeros [sic] residentes en esta ciudad, ha sugerido al infrascrito la idea de establecer un Club que estará bien servido y donde se leerán los principales periódicos del dia[sic]: también tendrá un Restaurant de primera clase provisto de vinos y licores etc.

Con este fin el abajo firmado ha compuesto y amueblado la casa que poco ha ocapó [sic] Don Pedro Rucabado, sita en la calle de la Independencia, cerca de la plaza principal; la que con el título de CLUB DE LA UNION se hallará abierta desde el Lunes 22 del corriente para todas las personas que con su asistencia quieran honrar al empresario.

T. H. H. Cauty ${ }^{9}$.

En conformidad con Cauty, los clientes potenciales del Club de la Unión eran los extranjeros establecidos en San José. Sin embargo, el empresario inglés no se limitó a ofrecer entretenimientos, sino también comida y licores, lo cual ampliaba el alcance comercial del naciente negocio. Además, debe destacarse la ubicación del club en una casa aledaña a la plaza principal, o sea, en el centro de la ciudad. De ese modo, Cauty fomentó tempranamente en Costa Rica la participación de costarricenses y extranjeros en dinámicas propias de un club de caballeros inglés. Como se verá más adelante, el Club Internacional fue una organización civil heredera del espíritu asociativo estimulado por Cauty a inicios del período republicano.

Ahora bien, ¿cuándo surgió el Club Internacional? En agosto de 1885 el Club Internacional celebró su quinto aniversario ${ }^{10}$, lo que lleva a deducir que su fundación fue en 1880. Una breve reseña histórica del club, publicada en La Nueva Prensa en 1928 , señala 1880 como un año importante para dicha asociación, pero a la vez niega que fuese entonces cuando se iniciaron las gestiones para fundar el Internacional ${ }^{11}$. Según el redactor de ese periódico, fue en 1876 cuando un grupo de ciudadanos notables, en colaboración con el Gobierno ${ }^{12}$, “[...] deseando fomentar la sociabilidad, pusieron la base fundamental de este centro de reunión social, que el año de 1880, inició su apogeo dando a la sociedad de la época las más hermosas fiestas sociales" ${ }^{\text {"13. En }}$ conformidad con el autor, algunos de los promotores del club fueron: Ernesto Rohrmoser von Chamier (1843-1882), Ramón Herrán López, Eduardo Beeche Argüello, Gordiano Fernández Ramírez, el doctor José María Castro Madriz (18181892), Juan Manuel Carazo Peralta (1814-1892), Mariano Montealegre Gallegos (1848-

\footnotetext{
${ }^{9}$ T. H. H. Cauty, "Club de la Unión”, Nueva Era, 18 de abril de 1861, 4.

${ }^{10}$ Diario de Costa Rica, "El”, 14 de agosto de 1885, 2.

${ }^{11}$ La Nueva Prensa, "Inauguración del Nuevo Edificio del Club Internacional", 29 de diciembre de 1928, 15.

${ }^{12}$ Según el redactor, el presidente general Tomás Guardia Gutiérrez estimuló la fundación del Club Internacional; de modo que la creación debió haber sido durante los primeros cuatro meses de 1876, pues en mayo de ese año Guardia le entregó el poder al licenciado Aniceto Esquivel Sáenz (1824-1898). La Nueva Prensa, "Inauguración del Nuevo Edificio del Club Internacional", 29 de diciembre de 1928, 15.

${ }^{13}$ La Nueva Prensa, "Inauguración del Nuevo Edificio del Club Internacional", 29 de diciembre de 1928, 15.
} 
1908) ${ }^{14}$, el doctor Cruz Alvarado Velazco, el licenciado Bruno Carranza Ramírez (1822-1891), Saturnino Tinoco, Rafael Alvarado Barroeta y Nicolás Sáenz ${ }^{15}$.

Tras revisar sistemáticamente los números de 1876 de la Gaceta Oficial y de $E l$ Costarricense, dos de las publicaciones semanales más importantes del período, no se encontró ninguna mención sobre el Club Internacional. Ahora bien, en el número de $E l$ Costarricense del 12 de julio de 1876 se anuncia la fundación de un club nuevo, el cual era presidido por el licenciado Manuel Arguello Mora (1834-1902) ${ }^{16}$. A finales del mismo mes se anunció que el club nuevo, llamado Club Nacional ${ }^{17}$, estaba instalado oficialmente en una casa aledaña a la calle de la Estación ${ }^{18}$. Considerando la caracterización del Internacional que difundió en 1928 el articulista de La Nueva Prensa, además de la coincidencia temporal, se hipotetiza que el Club Nacional pudo ser una primera fase del Club Internacional. A continuación se desarrollará dicha hipótesis.

Todavía en 1876, a lo largo del mes de septiembre se anunció en prensa que la noche del sábado 7 de octubre los miembros jóvenes del Club Nacional ofrecerían un baile $^{19}$. Tal convocatoria pública fue suscrita por el secretario del Club: Joaquín Bernardo Calvo Mora (c 1852-1915). Calvo tenía entonces aproximadamente 24 años de edad y probablemente estaba en sus últimos años de estudios en la Escuela de Derecho de la Universidad de Santo Tomás (en adelante: UST), o bien, recién se había graduado como abogado ${ }^{20}$. En comparación con el licenciado Argüello y con los miembros del listado publicado en La Nueva Prensa, Calvo era mucho más joven, lo cual muestra que el Club Nacional estaba integrado por ciudadanos de distintas generaciones. Empero, si bien Calvo era menor que los demás socios, el joven estaba vinculado con la UST, una de las instituciones más relevantes en la vida cultural josefina de la época, por lo cual no extraña su participación en el club. De hecho, desde mayo del mismo año la UST le prestaba un local a la Sociedad Científico-Literaria (en adelante: SCL), una suerte de club literario donde se reunía la élite intelectual

\footnotetext{
${ }^{14}$ Destaca la participación de Mariano Montealegre en la fundación del Club Nacional, pues Montealegre realizó sus estudios en Inglaterra y su familia tenía una estrecha relación con dicho país. ¿Por qué se resalta esto? Probablemente Montealegre conoció los clubes ingleses de caballeros y participó de ellos, pues su familia ostentaba un considerable poder adquisitivo y su padre vivió muchos años en Inglaterra. De modo que tal vez las experiencias de Montealegre fueron importantes en la estructuración del Club Nacional o el primer Club Internacional. Elías Zeledón Cartín, Del viejo San José (San José: EUCR, 2004), 61-63.

${ }^{15}$ La Nueva Prensa, "Inauguración del Nuevo Edificio del Club Internacional", 29 de diciembre de 1928, 15.

${ }^{16}$ El Costarricense, "Nuevo Club", 12 de julio de 1876, 1.

${ }^{17}$ No se ha logrado determinar si hay relación entre este Club Nacional y su homónimo fundado en 1865 por el doctor Castro Madriz. Blen, Historia del periodismo, 152.

${ }^{18}$ La casa era la que ocuparon antes las "Señoritas Fournier". El Costarricense, "Nuevo Club", 26 de julio de 1876, 2.

19 J. B. Calvo, "Club Nacional", Gaceta Oficial, 16 de septiembre de 1876, 6. J. B. Calvo, "Club Nacional", Gaceta Oficial, 30 de septiembre de 1876, 4.

${ }^{20}$ Joaquín Bernardo Calvo se formó en la UST bajo la tutela del guatemalteco Dr. Lorenzo Montufar. Ronald Soto-Quirós, "La difusión del etnotipo costarricense: los Apuntamientos de J. B. Calvo, del texto educativo a la propaganda internacional", Boletín AFEHC, no. 54 (julio-septiembre 2012), vínvulo caído.
} 
costarricense $^{21}$; allí, jóvenes como Francisco Chávez Castro (1850-1889) y Pío J. Víquez Chinchilla (1848-1899) departían con maestros de la talla del doctor Castro Madriz, el presbítero doctor Carlos María Ulloa (1833-1903), el licenciado Juan Fernández Ferraz (1849-1904) y el doctor Lorenzo Montufar y Rivera (1823-1898)22. De modo que el Club Nacional parece haber tenido un interés similar por incorporar a representantes de la juventud costarricense.

A juzgar por el listado de los supuestos fundadores de lo que acá se plantea era el Club Nacional ${ }^{23}$, se evidencia cómo en esta asociación convergían miembros, nacionales y extranjeros, de las élites económica, política e intelectual del país. Así, lo más probable es que los jóvenes que se asociaron al club fuesen también miembros de dichas élites. Por otro lado, debe distinguirse el perfil del Club Nacional con respecto a la SCL. Mientras que la SCL se proyectó como una academia que estimularía "[...] la difusión de las luces, presentando un teatro en donde pueda exhibirse la inteligencia en todo su desarrollo, hasta adquirir su perfección" ${ }^{\prime 2}$, el Club Nacional parece haber concentrado sus esfuerzos en promover la sociabilidad entre las clases altas de Costa Rica. A pesar de las diferencias en cuanto a los objetivos de sendas asociaciones, en ambos casos puede advertirse un relevo generacional a lo interno de las cúpulas que dominaban los campos intelectual y sociocultural del país. Siendo así, es bastante significativo que los miembros jóvenes del Club Nacional se encargaran de organizar bailes, pues, como se verá más adelante, nueve años después el Club Internacional era el encargado de tales actividades, estando entre sus afiliados varios de los exintegrantes del Club Nacional de 1876.

Otro factor que debe tomarse en cuenta para entender la fundación del Club Nacional y el auge que tuvo el Club Internacional durante la década de 1880, corresponde a la crisis que experimentó la masonería costarricense entre 1876 y $1883^{25}$. De acuerdo con el historiador Ricardo Martínez Esquivel, el desvanecimiento de la masonería, hacia 1876, reconfiguró el escenario sociocultural josefino, pues:

[...] muchos de los miembros de las redes políticas e intelectuales de Costa Rica que habían sido iniciados como masones, así como muchos otros participantes en estas redes, para los años siguientes $[\mathrm{a} 1876]^{26}$, más que anhelar la reorganización de la masonería, emigraron hacia las sociedades literarias y científicas, las instituciones educativas krausistas, las escuelas de adultos y los

\footnotetext{
${ }^{21}$ El Costarricense, "Sociedad Científico Literaria", 24 de mayo de 1876, 2.

${ }^{22}$ Blen, Historia del periodismo, 197.

${ }^{23}$ La Nueva Prensa, "Inauguración del Nuevo Edificio del Club Internacional", 29 de diciembre de 1928, 15.

${ }^{24}$ El Costarricense, "Club literario", 3 de marzo de 1874, 1.

${ }^{25}$ Martínez Esquivel, Masones y masonería, 70-75.

${ }^{26}$ Año de la abjuración de Francisco Calvo a la masonería, esto por presiones políticas. La renuncia del presbítero empeoró la ya de por sí condición crítica de la masonería costarricense. Martínez, Masones y masonería, $74-75$
} 
clubes sociales, encontrando en ellas el capital social y cultural, así como el espacio de acción política que pudo haberles significado la masonería ${ }^{27}$.

Aunque las logias masónicas no eran clubes sociales, a lo largo de los siglos XVIII y XIX muchos masones europeos y americanos utilizaron la masonería como una plataforma para socializar, negociar y hacer política ${ }^{28}$. De hecho, según el historiador Pierre-Yves Beaurepaire, las logias masónicas dieciochescas fueron "el refugio de la sociabilidad de las élites urbanas [europeas] sensibles a los discursos y proyectos de las luces". ${ }^{29}$ De manera similar, las investigaciones de Ricardo Martínez y los historiadores Gilberto Loaiza Cano y Pilar González Bernaldo de Quirós identifican a la masonería latinoamericana del siglo XIX como una práctica asociativa imbuida en el proceso de modernización sociocultural experimentado por las sociedades americanas a lo largo de esa centuria ${ }^{30}$. En ese sentido, la masonería puede considerarse una de las primeras formas de sociabilidad moderna potenciadas por las élites latinoamericanas ilustradas.

En el caso de la masonería costarricense decimonónica (iniciada en 1865), Martínez define a la logia masónica como "un espacio de difusión de los valores propios de la ideología del progreso, de la civilización, de la democracia y de las libertades de expresión, de asociación o de afiliación religiosa" ${ }^{\text {31 }}$. Por ello, llama la atención que el Club Nacional haya surgido en plena crisis de la masonería costarricense e incluso de modo paralelo a la renuncia de Francisco Calvo (1820-1890), entonces gran maestro del Gran Oriente y Supremo Consejo Centro Americano. Además, debe considerarse la persecución que había emprendido el deán doctor Domingo Rivas Salvatierra (1836-1900), entonces vicario capitular de la Diócesis de Costa Rica (1871-1876), contra la masonería y todas las corrientes ideológicas que no derivaran del dogma cristiano-católico ${ }^{32}$. Así las cosas, posiblemente quienes estaban en la masonería por intereses extra masónicos abandonaron dicha práctica asociativa y proyectaron otras, entre ellas los clubes.

Ahora bien, no se plantea acá que las logias se transformaran en clubes, sino que algunos masones participaron en la fundación de clubes, unos no regresaron a la masonería y otros se mantuvieron en diversos espacios asociativos a la vez. Un claro ejemplo de lo anterior corresponde a los supuestos miembros fundadores del Club

\footnotetext{
${ }^{27}$ Martínez, Masones y masonería, 75.

${ }^{28}$ Céline Sala, "La sociabilidad masónica francesa en la encrucijada de las fronteras fraternales y profanas: el ejemplo de la ciudad de Perpiñán en el siglo XVIII", REHMLAC 1 no. 2 (diciembre 2009abril 2010): 2-16, https://revistas.ucr.ac.cr/index.php/rehmlac/article/view/6614/26722. González, "La 'sociabilidad' y la historia política". Loaiza, Hombres de sociedades. Martínez, Masones y masonería. Pierre-Yves Beaurepaire, "Sociabilidad y Francmasonería. Propuestas para una historia de las prácticas sociales y culturales en el Siglo de la Luces", en 300 años: Masonerías y Masones (1717-2017). Tomo V. Cosmopolitismo, eds. Martínez Esquivel, Yván Pozuelo Andrés y Rogelio Aragón (Ciudad de México: Editorial Palabra de Clío, 2018), 22-30.

${ }^{29}$ Beaurepaire, "Sociabilidad y Francmasonería", 24.

${ }^{30}$ González, "La 'sociabilidad' y la historia política", 41. Loaiza, Hombres de sociedades, 96-97. Martínez, Masones y masonería, 53-60.

${ }^{31}$ Martínez, Masones y masonería, 245-246.

${ }^{32}$ Martínez, Masones y masonería, 72-73.
} 
Internacional (seguramente Club Nacional), pues cuatro de las doce personas mencionadas eran masones: Ernesto Rohrmoser, José María Castro Madriz, Cruz Alvarado y Bruno Carranza. ${ }^{33}$ Lo anterior no es extraño, ya que tanto la masonería como los clubes Nacional e Internacional compartieron ideales ilustrados, liberales, republicanos y progresistas.

Regresando al estudio del accionar del Club Nacional, el 11 de octubre de 1876 Joaquín Bernardo Calvo, secretario del club, remitió a la Gaceta Oficial un anuncio donde convocaba a los socios a una reunión general ${ }^{34}$, a celebrarse a las 6 de la tarde del miércoles 18 del mismo mes ${ }^{35}$. El objetivo de la reunión era discutir los estatutos que regirían el club y nombrar una nueva Junta Directiva. Dicha publicación revela cómo a tres meses de fundado el club e incluso con un directorio en ejercicio, los miembros todavía no habían resuelto cuáles eran las reglas del grupo. Sin embargo, la ausencia de una legislación interna no fue obstáculo para que los miembros jóvenes del Club Nacional realizaran el baile que habían anunciado desde septiembre de ese año. Al respecto de dicha actividad, el redactor de El Costarricense indicó:

El baile dado por los socios jóvenes de esta Corporación, estuvo magnífico, la concurrencia fué [sic] numerosa y la [ilegible] de refrescos abundante y exquisitamente servida. La animación y buen humor estuvieron á [sic] la orden. El doctor Zambrana, uno de los socios, improvisó en honor al bello sexo [mujeres] unas magníficas quintillas.

¡Ojalá se repitan escenas tan agradables!

Nuestras felicitaciones á [sic] los promovedores del baile.

El próximo Sábado [sic], según tenemos entendido, se propone el mismo Club, obsequiar á [sic] sus socios y los amigos de estós [sic] con un magnífico concierto, en uno de cuyos intermedios el mismo Señor Zambrana pronunciará un discurso de oportunidad.

Auguramos el éxito más satisfactorio á [sic] esta velada ${ }^{36}$.

El cronista se refirió al doctor Antonio Zambrana Vázquez (1846-1922), jurista, masón, político y filósofo cubano, quien había llegado a Costa Rica a finales de abril del mismo año. No obstante, en sus pocos meses en el país el cubano se había incorporado a la SCL, al Club Nacional e incluso fundó una Academia de Ciencias Sociales independiente ${ }^{37}$. En este caso, a diferencia de su rol como intelectual de la SCL y maestro en su efímera academia, Zambrana lució sus dotes como orador y poeta. Más

\footnotetext{
${ }^{33}$ La Nueva Prensa, "Inauguración del Nuevo Edificio del Club Internacional", 29 de diciembre de 1928, 15. Martínez, Masones y masonería, 104, 119, 187. Santamaría, "Análisis de la conformación”, 148.

${ }^{34} \mathrm{Al}$ día siguiente Calvo remitió a la Gaceta Oficial el siguiente anuncio: "A las ocho de la noche del sábado veintiuno del corriente, tendrá lugar en el salon [sic] principal [sic] del establecimiento, el concierto y los juegos de prestidijitacion [sic] que el empresario del Club Nacional ha proyectado". J. B. Calvo, "Club Nacional", Gaceta Oficial, 14 de octubre de 1876, 3. J. B. Calvo, "Club Nacional", Gaceta Oficial, 21 de octubre de 1876, 3.

${ }^{35}$ J. B. Calvo, "Club Nacional", Gaceta Oficial, 14 de octubre de 1876, 3.

${ }^{36}$ El Costarricense, "Club Nacional", 20 de octubre de 1876, 3.

${ }^{37}$ Armando Vargas Araya, El doctor Zambrana (San José: EUNED, 2006), 53-79.
} 
allá del talento del antillano, llama la atención lo que pudo ser el programa del evento, a saber: ágape, baile y apreciación de poesía improvisada. Al mes siguiente, el redactor de El Costarricense se refirió con pleitesía a un concierto de beneficencia que organizó el "bello sexo" (mujeres) y se celebró en el Club Nacional:

Para nosotros seria [sic] imposible entrar en apreciaciones artísticas ni dar cuenta detallada de la espléndida funcion [sic]. Sólo podemos afirmar que fué [sic] una fiesta digna de su objeto y de las personas que tomaron parte en ella. Era el salon [sic] como un gigantesco canastillo de preciosas flores exhalando sus perfumes en una atmósfera de armonías arrobadoras.

Hacer mencion [sic] nominal de las Señoritas [sic] que más se distinguieron y de las piezas en que más triunfos alcanzaron; y si, como es justo, debiéramos hacer lo mismo respecto de los caballeros, no aficionados, sino artistas, profesores, maestros; que las acompañaron; esquivaldria [sic] á [sic] reproducir uno por uno los catorce artículos que constituyen el programa ${ }^{38}$.

Conforme a lo expuesto por el cronista de El Costarricense, las mujeres fueron protagonistas de los bailes, los conciertos y las fiestas asociadas con el Club Nacional. Así, a diferencia de las dinámicas internas del club, exclusivas de caballeros, las actividades públicas integraron miembros de las élites de ambos sexos. Lo anterior fue común a las prácticas culturales de la burguesía europea y americana de la segunda mitad del siglo XIX, pues tanto en los clubes como en los eventos de élite se fomentaron determinados roles de género y se promovió la socialización entre los miembros jóvenes de la clase alta ${ }^{39}$.

Los clubes y los eventos de élite no solo reforzaron los roles de género y las sociabilidades burguesas, sino también se estimuló una subcultura en específico (recuérdese que, cuantitativamente, la élite era una minoría con respecto a las clases populares). A grandes rasgos, el modelo cultural al cual aspiraban las élites costarricenses puede definirse como uno de carácter europeizante y jerárquico ${ }^{40}$. Aunque muchos de los autodenominados ciudadanos ilustrados defendían ideas de corte liberal y progresista, su discurso en cuanto al orden sociocultural proponía una suerte de aristocracia democrática $^{41}$. En ese sentido, los miembros de la alta cultura josefina

\footnotetext{
${ }^{38}$ El Costarricense, "Club Nacional", 16 de noviembre de 1876, 2.

${ }^{39}$ Milne-Smith, London Clubland. María Angélica Salazar Rodríguez, "De encajes, sedas y moños: una historia del performance burgués y de la distinción social en Bogotá (1886-1899)" (Monografía de grado en historia, Universidad Colegio Mayor de Nuestra Señora del Rosario, 2012).

${ }^{40}$ Molina y Palmer, Héroes al gusto y libros de moda, 208-209. Santamaría, "Análisis de la conformación", 72-90.

${ }^{41}$ En el plano político, en algunos casos el carácter democrático se diluía para darle paso a ideas próximas a la tiranía o la monarquía; ejemplo de ello el autoritarismo que caracterizó a las administraciones consecutivas de los generales Tomás Guardia Gutiérrez (1870-1876 y 1877-1882), Próspero Fernández Oreamuno (1882-1885) y Bernardo Soto Alfaro (1885-1889). Orlando Salazar Mora, El apogeo de la república liberal en Costa Rica: 1870-1914 (San José: EUCR, 2003), 22-44.
} 
parecían estar a gusto con un modelo cultural acentuadamente elitista, pues este los legitimaba como lo mejor de la sociedad costarricense ${ }^{42}$.

Filosóficamente, las élites y los gobernantes costarricenses de la segunda mitad del siglo XIX promulgaron políticas culturales basadas en la teoría positivista del progreso, la cual surgió en Francia en la primera mitad del siglo XIX. ${ }^{43}$ Según la visión sociológica positivista, las sociedades podían alcanzar la civilización mediante el progreso material y el progreso moral; ${ }^{44}$ por supuesto, dicho ideal de civilización era eurocéntrico. En el caso de las repúblicas latinoamericanas, los defensores del buen gusto y de las buenas maneras tomaron por referente las ideas estéticas dieciochescas, los paradigmas morales y las sociabilidades impulsadas por las clases altas europeas. ${ }^{45}$ Por ello, la burguesía y los gobernantes costarricenses se caracterizaron por el consumo de manifestaciones artísticas derivadas del Academicismo y por el fomento de prácticas culturales imitadas de la aristocracia y la burguesía europea.

Los bailes, banquetes y conciertos privados, por ejemplo, fueron actividades apetecidas por los presidentes que gobernaron Costa Rica durante la segunda mitad del siglo $\mathrm{XIX}^{46}$. De modo que Juan Rafael Mora Porras (1814-1860) y Tomás Guardia Gutiérrez (1831-1882), presidentes emblemáticos de dos períodos del liberalismo costarricense, ofrecieron fastuosos festines en el marco de encuentros políticos de carácter nacional e internacional ${ }^{47}$. Debido a la relevancia de tales eventos, la asistencia se regulaba vía invitación, lo cual determinaba a las personas dignas de asistir a dichas galas. Al pasar los años este tipo de actividades oficiales no mermaron, empero, a aquellas se sumaron otras, ahora organizadas por los miembros de la burguesía costarricense, entre ellas el baile organizado por el Club Nacional en octubre de $1876^{48}$. Idénticamente, dichas agrupaciones civiles mantuvieron sus galas en un plano privado, lo cual las hacía un espacio que elevaba el estatus social de sus participantes.

Bajo las condiciones arriba señaladas, los clubes, los periódicos y las revistas ilustradas funcionaron como herramientas para que las élites josefinas promovieran determinado modelo cultural y a la vez aumentaran su prestigio social. No puede

\footnotetext{
${ }^{42}$ Dicha actitud se asemeja a la situación analizada por Gilberto Loaiza en los casos de las masonerías colombiana y cubana de la segunda mitad del siglo XIX. Loaiza, Hombres de sociedades, 127-130.

${ }^{43}$ Santamaría, "Análisis de la conformación", 95-105.

${ }^{44}$ Santamaría, "Análisis de la conformación", 97.

${ }^{45}$ María Fernanda Lander, "El Manual de urbanidad y buenas maneras de Manuel Antonio Carreño: Reglas para la construcción del ciudadano ideal", Arizona Journal of Hispanic Cultural Studies VI (2002). Santamaría, "Análisis de la conformación".

${ }^{46}$ Los bailes no fueron actividades exclusivas del período costarricense republicano, pues desde inicios del siglo XIX se realizaban; muestra de ello es el baile ofrecido en San José, en diciembre de 1834, al caudillo centroamericano General Francisco Morazán Quezada (1792-1842). John Lloyd Stephens, "Incidentes de viaje en Centro América, Chiapas y Yucatán", en Costa Rica en el siglo XIX: antología de viajeros, ed. Ricardo Fernández Guardia (San José: EUNED, 2002), 65.

${ }^{47}$ Félix Belly, "A través de la América Central, Nicaragua y el Canal Interoceánico", en Costa Rica en el siglo XIX, 452. María Clara Vargas Cullell, De las fanfarrias a las salas de concierto: música en Costa Rica, 1840-1940 (San José: EUCR, 2004), 85.

${ }^{48}$ En el caso de la práctica del baile recreativo, llama la atención un anuncio de prensa de 1858, en el cual José Sevilla, español, le ofrecía a la sociedad josefina lecciones de baile. Fumero, "La Ciudad en la Aldea", 99.
} 
ignorarse la participación en este proceso de políticos y militares, así como de acaudalados agricultores y comerciantes, pues al ser ellos los principales motores económicos de dicho proyecto cultural, estas plataformas los legitimaron como parte de la ilustración costarricense. El estudio de dicho proceso es interesante, ya que los ideólogos de tal proyecto cultural parecen no haber sido los políticos, los militares o los grandes comerciantes ${ }^{49}$, sino los intelectuales y los $\operatorname{artistas}^{50}$, quienes también aumentaron su estatus merced de determinados espacios asociativos. Así, la cultura ilustrada finisecular fue el producto de un complejo proceso simbiótico entre distintas asociaciones, entre ellas las logias, que compartían un mismo objetivo: promover el desarrollo de una cultura nacional ilustrada, liberal y progresista.

Como se verá en la tercera parte de este artículo, el Club Internacional fue una institución fundamental para la construcción de una identidad para las élites costarricenses, la cual se basó en un ideal cultural europeo, ilustrado y progresista. Sin embargo, antes de referir a las gestiones del Club Internacional en 1885 y su relación con tal proyecto cultural, a continuación se determinará la ubicación del club y se examinarán los estatutos que le rigieron entre 1884 y 1886.

\section{"Una asociación para el recreo y los negocios". Ubicación, estatutos y Salón del Arte del Club Internacional}

Tal y como se expuso en la sección anterior, el Club Nacional parece ser el antecedente del Club Internacional; no obstante, esto seguirá siendo una hipótesis hasta que se realice una investigación exhaustiva del período 1876-1880, misma que debería clarificar la suerte del Club Nacional, el proceso de gestación del Club Internacional y la relación de dichos fenómenos con la crisis de la masonería costarricense. Respecto de la fundación el Club Internacional, las fuentes indican que tal acontecimiento fue en 1880. ${ }^{51}$ Ahora bien, ¿dónde estaban las instalaciones del club? La reseña histórica de La Nueva Prensa indica que el primer establecimiento del club fue una casa ubicada al costado oeste del Parque Central, ${ }^{52}$ un punto bastante importante para el San José de $1880^{53}$. Posteriormente, el club se trasladó a una casa propiedad de los Montealegre y

\footnotetext{
${ }^{49}$ Sin pretender desmeritar los posibles aportes de dichos sectores a la construcción de un proyecto cultural nacional.

${ }^{50}$ Debe señalarse que varios políticos también eran reconocidos intelectuales y viceversa.

${ }^{51}$ Diario de Costa Rica, "El", 14 de agosto de 1885, 2. La Nueva Prensa, "Inauguración del Nuevo Edificio del Club Internacional", 29 de diciembre de 1928, 15.

${ }^{52}$ La Nueva Prensa, "Inauguración del Nuevo Edificio del Club Internacional", 29 de diciembre de 1928, 15.

${ }^{53}$ Antes de 1885 el Parque Central era conocido como la Plaza Mayor o la Plaza Principal. Ofelia Sanou y Florencia Quesada, "Orden, progreso y civilización (1871-1914). Transformaciones urbanas y arquitectónicas", en Historia de la Arquitectura en Costa Rica, eds. Elizabeth Fonseca y José Enrique Garnier (San José: Fundación Museos del Banco Central de Costa Rica, 1998), 293-294.
} 
luego a los altos de un edificio del comerciante cartaginés José Ramón Rojas Troyo (c 1834-1887), un inmueble de tres pisos conocido posteriormente como La Alhambra ${ }^{54}$.

Según un artículo conmemorativo al 75 aniversario del famoso homicidio del doctor Eusebio Figueroa Oreamuno (1827-1883), en 1883 el Club Internacional se encontraba en el edificio La Alhambra ${ }^{55}$. Años después, en conformidad con una crónica periodística de 1885, en agosto de ese año el Club Internacional estaba "instalado en la magnífica casa que sirvió de palacio al Jefe de esta diócesis" "56. Es decir, los liberales que expulsaron al Obispo Bernardo Augusto Thiel y Hoffman (1874-1901), en julio de 1884, le concedieron su antigua vivienda al Club Internacional, una asociación civil ilustrada y progresista ${ }^{57}$.

En la década siguiente, un aviso comercial de 1892 señala la instalación del almacén de Muñoz y Villalón en los bajos del Club Internacional, número 80 de la calle del Comercio (actual avenida central) ${ }^{58}$. Años más tarde, el Club Internacional le compró al licenciado Bernardo Soto Alfaro (1854-1931) su casa de San José (ubicada en el lote donde se instaló después el primer edificio del Club Unión) ${ }^{59}$, donde operó el club hasta el incendio del 28 de diciembre de $1918^{60}$. Tanto el edificio de Rojas Troyo como el de Soto se ubicaban en el centro de la ciudad, próximos a la zona donde estaba el Palacio Nacional y otros edificios públicos de importancia.

Una vez determinados los sitios donde estuvo el Club Internacional en las décadas de 1880 y 1890, de seguido se comentarán los estatutos de 1884. Asimismo, tras analizar los estatutos del Club Internacional, estos serán comparados con los Estatutos Civiles de la Masonería Centroamericana de $1884^{61}$, lo cual permitirá determinar las principales diferencias y semejanzas entre las constituciones reguladoras de ambas prácticas asociativas.

Hasta el momento se sabe poco de los primeros años del Club Internacional y de los estatutos que le hayan regido durante su primer trienio. Gracias a los estatutos de

\footnotetext{
${ }^{54}$ La Nueva Prensa, "Inauguración del Nuevo Edificio del Club Internacional”, 29 de diciembre de 1928, 15.

55 J. V. C., "75 años de la muerte del ilustre Dr. don Eusebio Figueroa Oreamuno", La Nación, 10 de agosto de 1958, 4. Tomás Federico Arias Castro, "El delito de duelo en Costa Rica (Análisis históricojurídico)", Revista Judicial, no. 101 (septiembre 2011): http://sitios.poderjudicial.go.cr/escuelajudicial/documentos/revs juds/revista\%20101/pdf/08 delitoduelo.pdf. Junta de Andalucía, Rehabilitación edificio La Alhambra. San José, Costa Rica (Andalucía: Consejería de Fomento y Vivienda de la Junta de Andalucía, 2011).

${ }^{56}$ Diario de Costa Rica, "Club Internacional", 28 de agosto de 1885, 1. Andrés Fernández, "Palacio Episcopal (Un regalo de bodas)", La Nación, 4 de abril de 2010, http://www.icomoscr.org/content/index.php?option=com content\&view=article\&id=99:noticia-2010-04$00 \&$ catid $=1$ :noticias-recientes\&Itemid $=18$

57 ¿Habrá sido esta una coincidencia o acaso el feroz liberalismo de Próspero Fernández pudo haber mediado este reemplazo simbólico? Al no poderse responder ahora dicha pregunta, al menos se señala ese detalle, el cual podría conducir una futura investigación sobre disputas por el poder por parte de agrupaciones religiosas, civiles, políticas, gremiales y artísticas, al ocaso del siglo XIX.

${ }^{58}$ Muñoz y Villalón, "Nuevo establecimiento", La Prensa Libre, 28 de junio de 1892.

${ }^{59}$ Desde entonces el Club Unión se ubica en el mismo sitio.

${ }^{60}$ La Nueva Prensa, "Inauguración del Nuevo Edificio del Club Internacional", 29 de diciembre de 1928, 15.

${ }^{61}$ Martínez, Masones y masonería, 267-280.
} 
1884 se ha podido clarificar el perfil del club y de sus miembros, así como la conformación del Directorio de ese año. Tal reglamento fue decretado en la asamblea general del 27 de enero de 1884 y entró en vigencia a partir del 10 de febrero siguiente. Dos años después, el 21 de marzo de 1886, dichos estatutos fueron reemplazados por unos nuevos, los cuales todavía estaban vigentes en 1897, según consta en una reimpresión de ese año ${ }^{62}$.

Los estatutos de 1884 fueron aprobados por la siguiente directiva: doctor Charles R. Lordly, presidente; Arthur Vansittart, tesorero; Camilo Mora Aguilar, secretario; Charles F. Willis y Manuel Carazo como vocales ${ }^{63}$. Dicho Directorio estaba integrado por tres extranjeros, probablemente británicos, y dos costarricenses, lo cual demuestra el carácter internacional del club. Mientras que Lordly era médico y masón ${ }^{64}$, Mora (quien también era masón) y Carazo estaban vinculados con la política nacional y la exportación de café ${ }^{65}$; no se sabe mucho de Vanssittart y Willis ${ }^{66}$. Como puede verse, al igual que en el caso del Club Nacional, el Club Internacional integró masones e incluso estos ostentaron puestos de poder en el club. Tal situación no significa que los masones dominaron el Club Internacional ni viceversa, sino que entre la burguesía costarricense finisecular fueron habituales las múltiples filiaciones asociativas, siempre y cuando estas no entraran en conflicto entre sí.

En relación con los objetivos del Club Internacional fijados en 1884 por la asamblea general y el Directorio, estos fueron instituidos desde el inicio de los estatutos:

El Club Internacional establecido en San José, es una asociación de individuos que, admitidos según las reglas que previenen estos Estatutos [sic], y rigiéndose por ellas, se juntan para su recreo ó [sic] sus negocios, y contribuyen con una cuota fija, destinada para el sostén y desarrollo del establecimiento. Su número es por ahora ilimitado 67 .

Con respecto a la administración del club, como se indicó antes, el Directorio estaba compuesto por un presidente, un tesorero, un secretario y dos vocales. El secretario era el encargado de ejecutar los acuerdos del Directorio, velar por el cumplimiento del reglamento interno del local y convocar a las juntas generales mediante circulares y avisos en la pizarra del club. Además, al secretario le correspondía llevar a cabo varios registros, a saber: un libro con las nuevas membrecías y los propuestos para sumarse al club; otro libro con los acuerdos del Directorio y de la Junta General; y un tercer libro donde se registraba el nombre y la nacionalidad de los

\footnotetext{
${ }^{62}$ Club Internacional de Costa Rica, Estatutos del Club Internacional de Costa Rica (San José: Gran Imprenta á Vapor - Cenedella \& Greñas, 1897), 15-16.

${ }^{63}$ Club Internacional, Estatutos del Club Internacional (San José: Imprenta Nacional, 1884), 11.

${ }^{64}$ Rafael Obregón Loría y George Bowden, La Masonería en Costa Rica. Segundo periodo (San José: Trejos Hermanos, 1938), 87.

${ }^{65}$ Obregón y Bowden, La Masonería en Costa Rica, 84.

${ }^{66}$ Quizás representaban casas comerciales extranjeras y se dedicaban al comercio local.

${ }^{67}$ Club Internacional, Estatutos del Club Internacional, 1.
} 
transeúntes y los socios responsables. Por su parte, el tesorero tenía a cargo los siguientes deberes: manejar los fondos del club; llevar la cuenta de las entradas y salidas del local, y presentarla al Directorio para su revisión; y elaborar un informe anual del estado económico del club, el cual debía ser estudiado por la "comisión revisora de cuentas" y luego presentado en la asamblea del primer domingo del año. Por último, los vocales eran los suplentes en caso de que en una reunión del Directorio se ausentaran el presidente, el tesorero o el secretario. La Junta Directiva era electa cada año y cabía la posibilidad de reelección indefinida.

En términos generales, el Directorio estaba encargado de la administración gubernativa y económica de la sociedad. Además, tenía la responsabilidad de modificar el reglamento interno (permisiones y prohibiciones) y convocar a las juntas generales. Dichas asambleas eran celebradas el primer domingo de cada año, esto para elegir al nuevo Directorio del club. En caso de que un grupo de socios quisiera convocar una Junta General, al menos diez miembros debían realizarle una solicitud escrita a la Junta Directiva.

Sobre las juntas generales, los estatutos establecen que estas se celebrarían a la 1 de la tarde del primer domingo del año. Toda Junta General debía ser anunciada mediante circular a los socios residentes en San José, con al menos ocho días de anticipación, quienes debían firmar el documento recibido. El objetivo de estas asambleas era elegir al nuevo Directorio y a la nueva comisión revisora de cuentas. Tal elección se realizaba a través de boletas escritas y se resolvía según la lógica de mayoría absoluta de votos, sin importar el número de socios presentes en la asamblea. Además, las juntas generales eran las encargadas de modificar, reformar o renovar los estatutos del club; para realizar esto, en una primera fase, al menos dos terceras partes de los socios debían estar de acuerdo con el cambio propuesto. Posteriormente, al menos ocho días después de la primera votación, una segunda Junta General debía ratificar la decisión tomada en la primera asamblea.

Respecto de la admisión al club, los estatutos indican que todos los miembros tenían el derecho de proponerle nuevos socios al secretario. Una vez tramitada la solicitud, una Junta General sesionaba para decidir, vía votación secreta, si el propuesto era aceptado o rechazado. Esta votación se hacía mediante fichas o bolas blancas y negras. En caso de que el candidato recibiera cinco votos negativos, su potencial membresía sería desautorizada automáticamente. Ahora bien, en caso de que el candidato recibiese la aprobación de los socios, el nuevo miembro sólo podría integrarse al club después haber pagado la cuota de introducción (30 pesos socios propietarios y 10 pesos socios asistentes) y el costo de la suscripción del mes $(2,5$ pesos para todos los socios).

Si bien los estatutos no lo establecen claramente, considerando los términos de los artículos del reglamento y las características de los miembros que se vincularon al Club Internacional durante sus años de actividad, se deduce una condición tácita a las normas de dicha asociación: el club era exclusivo para hombres. De modo semejante, los estatutos no determinan una edad mínima o máxima para afiliarse al club; es 
probable que los miembros menores fuesen jóvenes comerciantes y estudiantes del Instituto Nacional o de la UST, mientras que, se propone, no hubo un tope de edad para pertenecer al grupo. La capacidad económica fue otra condición que delimitó a la población que podía acceder al club, ya que cada socio debía pagar una cuota de introducción y posteriormente las cuotas mensuales. La membresía del Internacional presuponía una condición económica que permitiera costear mensualmente la filiación al club, pues si un socio se atrasaba con el pago de dos meses consecutivos podía ser "excluido de hecho" de la asociación.

Como ya se ha mencionado, el Club Internacional era tanto para costarricenses como para extranjeros, probablemente tal característica estuvo vinculada con la elección del nombre de la asociación. Tan importante era el carácter internacional del club, que los estatutos prohibían tajantemente las discusiones relacionadas con asuntos políticos nacionales e internacionales, lo cual anticipaba posibles situaciones en las algunos temas pudiesen ser ofensivos para algún o varios socios. También debe señalarse que al parecer varios de los miembros del club solían abandonar Costa Rica por largas temporadas, ya que el artículo 25 de los estatutos define qué hacer en caso de que un socio se ausentara del país por cinco meses o más. De este modo, en los estatutos se estableció, implícitamente, el perfil de los potenciales asociados al Internacional.

Los ciudadanos costarricenses o extranjeros vinculados con el club eran clasificados según varios tipos de categorías asociativas. A lo interno del club los socios se dividían en fundadores, propietarios y asistentes; asimismo, se permitía que el local fuese frecuentado por personas transeúntes debidamente registradas ${ }^{68}$. De todas las profesiones de la época, los estatutos sólo premian a los agentes de la carrera diplomática, quienes a priori tenían la posibilidad de ser presentados por algún socio al club y vincularse al mismo, siempre y cuando pagaran las cuotas correspondientes. Caso aparte eran el Presidente de la República y los Secretarios de Estado, pues sus cargos públicos les conferían automáticamente la condición de miembros honorarios del Club Internacional, empero, estos no podían votar en las elecciones y deliberaciones del club. Tal clausula parece estar pensada para los ciudadanos que integraran el Poder Ejecutivo y no estuvieran vinculados con el Internacional, pues los estatutos no establecen qué procedía si dichas personas fuesen miembros del club antes de acceder a tales cargos gubernamentales.

Ahora, ¿cuáles eran las diferencias entre cada clase de membresía? Los estatutos de 1884 no clarifican si los socios fundadores tenían mayores competencias que los propietarios o si su distinción respondía a un asunto meramente simbólico. En el caso de los socios asistentes, estos tenían los mismos derechos de los transeúntes, es decir, la posibilidad de asistir al local y participar de las actividades del club; sin embargo, los asistentes no tenían voto ni propiedad a lo interno de la agrupación. Si un socio asistente hubiese querido cambiar su condición a propietario, el interesado simplemente tuvo que

\footnotetext{
${ }^{68}$ Se consideraba transeúnte a toda persona cuya residencia se encontrara fuera de la provincia de San José. Tras treinta días de permiso gratuito, los transeúntes podían seguir asistiendo al Club Internacional si pagaban las cuotas correspondientes a cada mes.
} 
haber pagado una diferencia entre 30 y 10 pesos. Caso distinto a los transeúntes y a los socios asistentes, los propietarios tenían la posibilidad de ser elegidos como miembros de la comisión revisora de cuentas y probablemente del Directorio del club, no obstante, lo segundo no fue definido en los estatutos acá comentados. De cualquier manera, está claro que los socios fundadores y propietarios eran los encargados de tomar las decisiones en el Internacional, pues tenían voto en las asambleas y estaban en capacidad de integrar las instancias administrativas del club.

En conformidad con tales estatutos, el Directorio fungía un rol legislador, judicial y gubernativo a la vez. Si bien los demás asociados tenían la posibilidad de proponer el ingreso de miembros y participar de las juntas generales, tal parece que el Directorio ejecutaba y legislaba sin obstáculos. El único órgano ajeno al Directorio que poseía capacidades fiscalizadoras era la comisión revisora de cuentas; sin embargo, parece que su accionar se limitaba a revisar los informes anuales de la Junta Directiva. Ahora bien, si se considera la manera de elegir al Directorio y de determinar el ingreso de nuevos socios, se evidencia que el club funcionaba bajo un sistema de influencia democrática. Asimismo, debido a que el club creó una suerte de constitución (los estatutos) para regular su funcionamiento, la agrupación se adhirió a un modelo jurídico de inspiración republicana. Así, puede afirmarse que el Club Internacional funcionaba como una pequeña república democrática, lo cual no es de extrañar, pues muchos de sus miembros eran políticos y en aquellos días las ideas del republicanismo ilustrado y del liberalismo democrático ocupaban un lugar central en el discurso de la mayoría de los ciudadanos progresistas ${ }^{69}$.

Del mismo modo, el análisis de los estatutos de 1884 permite caracterizar el perfil general de los miembros del club. En ese sentido, el género, la edad, la profesión y la capacidad económica eran factores que autorizaban o desautorizaban a las personas que pretendieran asociarse al Club Internacional. Así, la necesidad de ser presentado por un socio para aspirar a vincularse al club, además de la ulterior votación en asamblea para determinar el ingreso al $\mathrm{club}^{70}$, eran maneras de controlar el tipo de población que se integraba a la asociación. Incluso, el primer artículo de los estatutos indica las dos principales actividades que reunían a los miembros del club: el recreo y los negocios. Bajo estas condiciones, el Club Internacional se constituía, debido a su exclusividad, un espacio que legitimaba a sus miembros como parte de lo mejor de la sociedad josefina.

Los Estatutos Civiles de la Masonería Centroamericana (1884) poseen una estructura similar a los estatutos del Club Internacional, pero quizás la mayor diferencia es el alcance regional (centroamericano) del reglamento masónico ${ }^{71}$. Aun así, ambos estatutos exigen respeto hacia las autoridades estatales y le confieren una filiación

\footnotetext{
${ }^{69}$ Además, aunque la República de Costa Rica había sido fundada 36 años atrás, en la práctica los ideales republicanos y democráticos habían sido violentado numerosas veces por el autoritarismo y los cuartelazos, entonces, quizás el Club Internacional fue un espacio para que las élites experimentaran lo que la realidad política del país no les ofrecía.

${ }^{70} \mathrm{O}$ bien, ser funcionario del Gobierno de la República (presidente, secretario de Estado o agente diplomático).

${ }^{71}$ Club Internacional, Estatutos del Club Internacional. Martínez, Masones y masonería, 267-280.
} 
especial al Presidente de la República, lo cual refleja el carácter republicano de ambas asociaciones. Otra coincidencia radica en la obligación de cotizar (masonería) o pagar membresía (Club Internacional); indudablemente esto limitaba el acceso a sendas sociedades, pero también era necesario para garantizar el funcionamiento de las mismas. Por último, también hay semejanzas entre la administración del club y las logias, pues la dirección era responsabilidad de un Presidente, un Secretario, un Tesorero y un Consejo integrado por tres miembros del Supremo Consejo.

Sin embargo, también hay notables diferencias entre ambos estatutos. En primer lugar destaca el gran énfasis de los masones hacia los "Principios y objeto de la sociedad", así como a los deberes y los derechos de los miembros de la masonería (estos últimos muchos más detallados que en los estatutos del club). Tal característica se debe a la naturaleza de la asociación, pues, a diferencia del Club Internacional (creado para el entretenimiento y los negocios), las logias tienen un objetivo filosófico y filantrópico, lo cual le impone a sus miembros una serie de principios religiosos, morales, fraternales, políticos, rituales, discrecionales e intelectuales. Por ejemplo, mientras en el Club Internacional la reincorporación de un miembro excluido dependía de un asunto económico y probablemente de la asamblea general, en las logias se requería de una rehabilitación (posiblemente moral). Finalmente, contrario a lo establecido en los estatutos Club Internacional, la masonería costarricense no admitía transeúntes, esto debido al tipo de asociación y a sus objetivos.

Como puede verse, si bien ambas asociaciones guardan semejanzas en cuanto al perfil de sus miembros (hombres respetuosos de las leyes y admitidos mediante votación tras ser propuestos por un asociado), los estatutos revelan el disímil objetivo general de sendas sociabilidades. Mientras las logias tenían una función "filosófica, progresista, civilizadora y filantrópica", el Club Internacional era una asociación creada para el recreo o los negocios de sus miembros ${ }^{72}$. Considerando lo anterior, es comprensible porqué varias personas participaron de las dos sociabilidades, pues cada una les ofrecía algo bastante distinto, pero estas no eran incompatibles entre sí.

Tras analizar los estatutos del Club Internacional de 1884 y en orden a determinar las características específicas de un sector de los socios del club, a continuación se revisará el testimonio de uno de los jóvenes que asistió al Internacional durante los últimos años del siglo XIX: el célebre escritor costarricense Manuel González Zeledón (1864-1936), quien se dio a conocer con el nombre artístico de Magón. Gracias a lo narrado por Magón en las memorias de sus vivencias en el Club Internacional, dicha asociación se vislumbra como un foco importante del fomento de las artes en la Costa Rica finisecular y como un valioso tema por desarrollar por parte de la historiografía del arte costarricense. Seguidamente se expondrá porqué.

En 1924 González Zeledón escribió en Nueva York el relato "¡Todo pasa...!", en el cual integró información valiosa sobre el Internacional de finales del siglo XIX, el rol de varios de sus miembros y algunas de las dinámicas del llamado Salón del Arte de

\footnotetext{
${ }^{72}$ Club Internacional, Estatutos del Club Internacional, 1. Martínez, Masones y masonería, 268.
} 
dicho club. ${ }^{73}$ En conformidad con Magón, había un "saloncillo de música", en el cual los socios se dedicaban a la lectura o a jugar billar, póker, dominó y chaquete; en el mismo salón estaba el piano "el Apollo", comprado al comerciante Juan Rafael Mata Brenes. De acuerdo con la descripción del saloncillo de música, parece que dicho espacio fue el mismo que Magón llamaba Salón del Arte ${ }^{74}$.

Además del Salón del Arte, el Club Internacional contaba con un Salón de Recibo, una Sala de Billares y una biblioteca ${ }^{75}$. Sin embargo, debe señalarse que, aunque la biblioteca del club fue un proyecto iniciado en enero de $1885^{76}$, las instalaciones del club descritas por Magón refieren al local de 1918. Joaquín Bernardo Calvo, quien era socio del Internacional, escribió una descripción del club un año después de iniciada la biblioteca:

El Club Internacional, asociación que comprende la mejor parte de la sociedad costarricense, es el establecimiento recreativo más respetable del país. Ocupa un local espacioso y bien distribuido; tiene muy buenos salones de recibo y de lectura: en él se encuentran periódicos en distintos idiomas, y una biblioteca con 5,000 volúmenes escogidos entre las mejores obras literarias y científicas, escritas en alemán, inglés, francés, italiano y español ${ }^{77}$.

Calvo, aquel joven miembro del Club Nacional de 1876, ahora vinculado con el gobierno del general Bernardo Soto y encargado de la producción de una obra historiográfica oficialista, le confirió al Club Internacional un alto grado de relevancia cultural. Como puede verse, a un año de fundada la biblioteca, el acopio alcanzaba los 5000 volúmenes, los cuales estaban en distintos idiomas, todos relacionados con las principales migraciones que arribaron a Costa Rica durante la segunda mitad del siglo XIX. Los idiomas de los libros no sólo refieren a los extranjeros que pertenecían o frecuentaban el club, sino a una comunidad de costarricenses ilustrados que manejaban varias lenguas y probablemente valoraban positivamente muchos títulos de la literatura europea.

Regresando al texto de Magón, parece que el Salón del Arte tenía un grupo de más de treinta miembros que se reunían en tal espacio para dedicarse a sus intereses comunes $^{78}$. Sobre el testimonio literario de Magón, debe indicarse que no se tiene claro si el literato fue miembro fundador del Club Internacional, de haber sido así, para

\footnotetext{
${ }^{73}$ Manuel González Zeledón, Cuentos de Magón (San José: Imprenta Nacional, 2012), 145-148.

${ }^{74}$ González Zeledón, Cuentos de Magón, 145-148.

${ }^{75}$ Los relatos en torno al homicidio del Dr. Figueroa indican que en 1883 el Club Internacional contaba con al menos una mesa de billar. A J. V. C., "75 años de la muerte del ilustre Dr. don Eusebio Figueroa Oreamuno", 4.

${ }_{77}^{76}$ Diario de Costa Rica, "Club Internacional", 15 de enero de 1885, 2.

77 Joaquín Bernardo Calvo, Apuntamientos geográficos, estadísticos é históricos (San José: Imprenta Nacional, 1887), 178-179.

${ }^{78}$ Ante esto surgen las siguientes interrogantes: ¿Estuvo el Club Internacional subdividido según los intereses de sus miembros? ¿Habría una suerte de Salón de Negocios? ¿Cuáles fueron los subgrupos que integraron el Club Internacional durante las décadas de 1880 y 1890 ? El presente estudio no pretende responder a tales preguntas, pero sí considera necesario plantearlas y sugerir posibles vías de investigación.
} 
entonces González Zeledón contaría con apenas 16 años de edad, lo cual no significa que no haya podido vincularse al club en ese momento o poco tiempo después. Además, a juzgar por las personas mencionadas por el escritor, parece que sus crónicas del Salón del Arte se remontan a las postrimerías de la década de 1880 y principalmente al último decenio del siglo XIX. De todos modos, lo más probable es que algunos de los miembros mencionados hayan pertenecido al club desde su fundación o que se hubiesen vinculado durante su primer lustro de operaciones.

Ahora bien, ¿quiénes fueron los compañeros de Magón en el Salón del Arte de las últimas dos décadas del siglo XIX? Con respecto a los amantes de las letras, Magón menciona al doctor Zambrana, a su primo, el famoso literato Aquileo J. Echeverría Zeledón (1866-1909), al periodista y militar colombiano Rafael Villegas Arango (\$ 1922) y a un tal Viniegra. Además, González destacó las "sabrosas pláticas" que tenían "Matita" (quizás Juan Rafael Mata Brenes, hijo de Juan Rafael Mata Lafuente) y Camilo Mora Aguilar, quien era hijo Juan Rafael Mora Porras (1814-1860) y también era político ${ }^{79}$. Por su parte, el abogado Alberto Gallegos Pacheco (1868-1909), Manuel Carazo y el profesor nicaragüense Juan Montalto entablaban "sesudas disquisiciones" 80 . Finalmente, Magón recordó las "acaloradas discusiones arquitectónicas" entre tres profesionales que fueron importantísimos para el campo de la construcción en la Costa Rica de la década de 1890: el ingeniero italiano Enrico Invernizio Olivieri, "Durini" (probablemente González se refería a Lorenzo Durini Vasalli, un arquitecto y comerciante suizo-italiano o bien a su hermano Francisco Durini Vasalli, también comerciante) y el ingeniero costarricense Lesmes S. Jiménez Bonnefil (1860-1917) ${ }^{81}$.

Otra diversión del Salón del Arte consistía en tocar el piano y cantar, actividades de las cuales Magón participó. Los pianistas mencionados por Magón son Jesús Salazar, "el Renco" Juan Vicente "Chente" Quirós Flores (1853-1900), el licenciado Francisco "Chico" Vicente Sáenz Esquivel, Fernando Goicoechea y el ingeniero Alejo Jiménez Bonnefil ${ }^{82}$. En el caso de los cantantes, González Zeledón recordó al tenor lírico spinto y agricultor Alejandro "Cano" Aguilar Mora (1870-1956), a un tal Mata (¿Juan Rafael Mata Brenes?), al tenedor de libro británico Ernesto Foster Austin y al político Tobías Zúñiga Castro (1854-1918), este último fue identificado por Magón como "Gato". Otros socios del Internacional que disfrutaron en el Salón del Arte fueron: el poeta Elías Castro Ureña, Víctor Millet, Antonio Ortuño, Alfredo Esquivel, José María Castillo, el licenciado Pedro Loría Iglesias y el profesor francés Luis Charpentier ${ }^{83}$.

Como puede verse, el Salón del Arte del Club Internacional fue un importante punto de encuentro para profesionales y aficionados a las Bellas Artes en el San José

\footnotetext{
${ }^{79}$ Camilo Mora Aguilar fue elegido gobernador de San José en 1885.

${ }^{80}$ González Zeledón, Cuentos de Magón, 147.

${ }^{81}$ Sobre la actividad artístico-comercial de los Durini Vasalli en Centroamérica y sus vínculos con la masonería ver: Mauricio Oviedo Salazar y Leonardo Santamaría Montero, "Los Durini: redes de mercado cultural en Centroamérica" (Informe final de investigación, Instituto de Investigaciones en Arte, Universidad de Costa Rica, 2016).

${ }^{82}$ González Zeledón, Cuentos de Magón, 147.

${ }^{83}$ González Zeledón, Cuentos de Magón, 147.
} 
finisecular. Así, en correspondencia con las fuentes consultadas, el Club Internacional se antoja como uno de los núcleos de la cultura ilustrada ${ }^{84}$, la cual rigió muchas de las actividades organizadas y consumidas por las élites costarricenses de las dos últimas décadas del siglo XIX. De modo que el Internacional no se limitó a ser un simple espacio para negociar, leer, tertuliar y practicar las artes, sino que esta agrupación también tuvo un rol activo en la vida social josefina, pues se avocó a la celebración de bailes, cenas e incluso espectáculos públicos ${ }^{85}$. En relación con su gestión como productor de eventos, de seguido se analizará un evento organizado en 1885 por el Club Internacional y un proyecto gubernamental que se gestó en el club ese mismo año.

\section{La Junta del Teatro y el baile del quinto aniversario del Club Internacional (1885)}

El domingo 4 de enero de 1885 se realizaron las elecciones para definir la Junta Directiva que administraría al Club Internacional a lo largo del año que recién iniciaba. Como puede verse (cuadro 1), el Directorio electo estaba compuesto por hombres dedicados a la política y los negocios. Dos de los cinco miembros eran extranjeros, sin embargo, sus cargos eran de los más importantes de la junta (presidente y tesorero); mientras que los socios costarricenses eran los dos vocales y el secretario, este último sí era un puesto de gran responsabilidad. Debe recordarse que tanto Ernesto Rohrmoser, quien además era masón, como Manuel Carazo, fueron señalados por el articulista de $L a$ Nueva Prensa como parte de los fundadores de aquella agrupación de 1876 que antecedió al Club Internacional. A parte de Rohrmoser, Alejandro Alvarado y Camilo Mora también participaban de la masonería costarricense, lo cual corrobora las sociabilidades múltiples características de las élites.

Cuadro 1

Junta Directiva del Club Internacional electa para el período 1885-1886

\begin{tabular}{llll}
\hline Nombre & Cargo & Ocupación & Nacionalidad \\
\hline Ernesto Rohrmoser von Chamier $\therefore$ & Presidente & Comerciante & Alemán \\
Alejandro Alvarado García $\therefore$ & Vocal & Abogado y político & Costarricense \\
Juan Manuel Carazo Peralta & Vocal & Agricultor, militar y político & Costarricense \\
José María Callejas & Tesorero & Desconocida & Español \\
Camilo Mora Aguilar.$\therefore$ & Secretario & Político & Costarricense \\
\hline
\end{tabular}

* $\therefore$ Participantes de la masonería costarricense.

Fuente: Diario de Costa Rica, "Elecciones", 8 de enero de 1885, 2. Martínez, Masones y masonería, 218. Santamaría, “Análisis de la conformación”, 148. Obregón y Bowden, La Masonería en Costa Rica, 84.

\footnotetext{
${ }^{84}$ Junto a la UST, las logias masónicas, la SCL, algunas publicaciones (periódicos y revistas), el Teatro Municipal, el Teatro de Variedades y las asociaciones artísticas.

${ }^{85}$ Fumero Vargas, Teatro, público y estado en San José 1880-1914 (San José: Editorial de la Universidad de Costa Rica, 1996), 119.
} 
En relación con el estatus socioeconómico de los miembros del Directorio, puede verse como todos coinciden con el perfil esbozado líneas atrás. Otra condición interesante es la ausencia de artistas, ingenieros o intelectuales, estando la junta integrada por individuos dedicados a las principales profesiones de la burguesía costarricense de entonces: la abogacía (estrechamente vinculada con la política) y el comercio (considerando acá la agroexportación). Siendo así, esta Junta Directiva fue la encargada de organizar el evento de gala que será estudiado en este capítulo. No obstante, antes de pasar a dicho análisis, se comentará la Junta del Teatro de 1885 y la relación del Club Internacional con tal iniciativa.

Desde comienzos de 1885 se había abierto una discusión pública, en prensa, sobre el supuesto estado deplorable de las instalaciones del Teatro Municipal. Un articulista del Diario de Costa Rica informó en enero de iniciativas individuales para reparar el edificio o construir uno nuevo, las cuales requerían del apoyo del Gobierno y el municipio ${ }^{86}$. El autor justificó la necesidad de un buen local para el Municipal del siguiente modo: "[...] no hay quien dude ya de que la afición por tan instructivo y útil pasatiempo [el teatro] se generaliza y arraiga en esta sociedad" ${ }^{87}$. Efectivamente, el consumo teatral había crecido durante las dos últimas décadas; este proceso incorporó a consumidores de diversos sectores sociales, sin embargo, solo la "selecta sociedad" era protagonista de las reseñas, crónicas y críticas de espectáculos publicadas por los periódicos costarricenses ${ }^{88}$.

Es probable que las iniciativas mencionadas por el articulista del Diario de Costa Rica hayan persistido, pues el 19 de junio del mismo año se formó la Junta del Teatro (cuadro 2), nombrada por el Gobernador de San José y encargada de las obras de reparación del Teatro Municipal ${ }^{89}$. Cuatro días después se ratificaron los miembros de la junta en una reunión celebrada en el Salón de Recibo del Club Internacional, en la cual se definieron los cargos de algunos miembros y las comisiones que integrarían (cuadro 2) 90 .

\footnotetext{
${ }^{86}$ Diario de Costa Rica, "Teatro", 21 de enero de 1885, 2.

${ }^{87}$ Diario de Costa Rica, "Teatro", 21 de enero de 1885, 2.

${ }^{88}$ Fumero, Teatro, público y estado, 115-124.

${ }^{89}$ J. Raf. Echavarría, "N 975 ", La Gaceta, 21 de junio de 1885, 503.

${ }^{90}$ Diario de Costa Rica, "Teatro", 23 de junio de 1885, 2. Diario de Costa Rica, "Junta del Teatro", 26 de junio de 1885, 2.
} 
REHMLAC+, ISSN 1659-4223, vol. 10, no. 1, mayo-noviembre 2018/35-71 56

\section{Cuadro 2}

Miembros de la Junta del Teatro

\begin{tabular}{|c|c|c|c|c|}
\hline Nombre & Cargo & Comisión & Ocupación & Nacionalidad \\
\hline Joaquín Bernardo Calvo Mora & Secretario & Pintura y decoración & Abogado y diplomático & Costarricense \\
\hline Juan W. Valenzuela & & & Comerciante & Desconocida \\
\hline Gerardo Castro Méndez & & Pintura y decoración & Abogado & Costarricense \\
\hline Francisco Arrillaga y Ansola & & & Músico, profesor y diplomático & Español \\
\hline Tobías Zúñiga Castro & & & Político & Costarricense \\
\hline Camilo Mora Aguilar & & & Político & Costarricense \\
\hline Santiago de la Guardia & Presidente & & Secretario de Guerra y Marina & Panameño \\
\hline Manuel Aragón Quesada & Vicepresidente & Ingeniería y arquitectura & Ministro de Hacienda y Comercio & Costarricense \\
\hline Juan Rojas Troyo & Tesorero & & Comerciante & Costarricense \\
\hline Lesmes Jiménez Bonnefil & & Ingeniería y arquitectura & Director General de la DGOP & Costarricense \\
\hline Ezequiel Gutiérrez Iglesias & & Ingeniería y arquitectura & Diplomático, político y profesor & Costarricense \\
\hline Juan Francisco Echeverría Aguilar & & Ingeniería y arquitectura & Ingeniero y político & Costarricense \\
\hline
\end{tabular}

Fuente: Diario de Costa Rica, "Teatro Municipal”, 26 de junio de 1885, 1-2.

Con la excepción de Juan W. Valenzuela y Francisco Arrillaga, se tiene certeza que el resto de la Junta del Teatro estaba vinculada con el Club Internacional; sin embargo, lo más probable es que Valenzuela y Arrillaga también fuesen miembros del club josefino. Como puede verse, las ocupaciones de los integrantes de la junta están dominadas por la política, los negocios y la abogacía. A diferencia del Directorio del Club Internacional de ese año, en la Junta del Teatro predominan los miembros costarricenses. El decreto municipal que formó dicha junta certifica el estatus social del que gozaban este grupo de ciudadanos, pues en él el Gobernador J. Rafael Echavarría les calificó de patriotas e ilustrados ${ }^{91}$.

Por otro lado, debe resaltarse el rol cumplido por el Diario de Costa Rica al margen de dicho proyecto, ya que dicho periódico fue el encargado de informar de todo lo relacionado con la Junta del Teatro. En esos momentos Joaquín Bernardo Calvo, quien era socio del Club Internacional, secretario de la Junta del Teatro, era el propietario y editor del Diario de Costa Rica, lo cual explica la importancia conferida por el periódico josefino a tal empresa ciudadana. Por supuesto, el tratamiento del tema, por parte del diario, fue abiertamente favorable a la causa del grupo de ciudadanos encargados de mejorar el edificio y las decoraciones del Teatro Municipal ${ }^{92}$.

Otra característica relevante es la participación de autoridades del Gobierno de la República y los diversos órganos representados a lo interno de la Junta del Teatro. Tras ser convocada por el Gobernador de la ciudad donde estaba el teatro, la junta fue presidida por el Secretario de Guerra y Marina, cuyo vicepresidente era el Ministro de Hacienda y Comercio, quien además integró la comisión de Ingeniería y Arquitectura. También el Director de la Dirección General de Obras Públicas formó parte de la junta y se sumó a la mentada comisión de Ingeniería y Arquitectura. Dadas las condiciones, parece que el Gobierno estaba anuente a colaborar administrativamente y potencialmente financieramente con las obras de restauración del Teatro Municipal.

\footnotetext{
${ }^{91}$ J. Raf. Echavarría, "No 975”, La Gaceta, 21 de junio de 1885, 503.

92 J. B. Calvo, "Teatro Municipal", Diario de Costa Rica, 26 de junio de 1885, 1-2.
} 
La Junta del Teatro se creó en los primeros meses del gobierno provisional del general Bernardo Soto, quien asumió la Presidencia de la República a los 31 años de edad, tras la muerte de su suegro el general Próspero Fernández Oreamuno (18341885). Continuando la senda trazada por la dictadura del general Tomás Guardia (18771882) y el gobierno del general Fernández (1882-1885), el presidente Soto promovió una serie de reformas estatales inspiradas en los ideales liberales y positivistas. Las reformas liberales, como se les conoce, incidieron en los campos legal, religioso, educativo, moral, cultural, urbanístico e historiográfico; por ello no es de extrañar que Soto apoyara a la Junta del Teatro, pues el proyecto de dicha comisión respondía a las mismas motivaciones ideológicas del joven presidente. Además, considerando que Soto era un abogado egresado de la UST, lo más probable es que estuviera vinculado directa o indirectamente con el Club Internacional, pues muchas personas cercanas a él eran miembros de esa sociedad. Asimismo, debe recordarse que los estatutos otorgaban membresía honoraria a las máximas autoridades del Poder Ejecutivo; lo cual coincide con que los miembros de la junta eran socios del Internacional desde antes de ser convocados por el Gobierno de la República.

La participación del Club Internacional en este asunto gubernamental indica que el club llevó a aliarse con el Estado para desarrollar objetivos comunes. Además, dicho vínculo revela que el ala más política del Club Internacional había ascendido a los cargos más jerárquicos de la política nacional. Entonces, un grupo de socios del Club Internacional, ahora consagrados por el Gobierno bajo la denominación Junta del Teatro, se reunieron por varias semanas en el Salón de Recibo del club para resolver si debía restaurarse el Teatro Municipal o si lo mejor era construir un teatro nuevo. De igual manera, un factor sumamente importante es la motivación misma del proyecto: tener un buen teatro. ¿Quiénes querían tener un buen teatro? El Estado (la Municipalidad de San José), ciertamente, pero en el nivel práctico quienes utilizaban más el teatro eran los consumidores de espectáculos artísticos. Ahora, es cierto que el teatro no era exclusivo de las élites, pues las clases populares también disfrutaron durante el período de actividad del Teatro Municipal (1850-1888), sin embargo, parece que el teatro, y principalmente las sociabilidades en torno a él, fue un componente importantísimo para la agenda de la burguesía costarricense de la época.

$\mathrm{Si}$ se considera el Club Nacional como antecedente, los ideales del Club Internacional y los ciudadanos involucrados en el proyecto de la Junta del Teatro, se clarifica cómo representantes de los sectores más elevados de la sociedad decidieron proponerle al Gobierno (en el cual había compañeros del club) que juntos remodelaran el teatro de la ciudad, o bien, construyeran uno nuevo. Románticamente, un articulista del Diario de Costa Rica se refirió de la siguiente manera al proyecto de la Junta del Teatro:

Da pena, verdaderamente, la vista del templo que al arte se ha consagrado entre nosotros. 
En esta capital hay regulares edificios destinados á [sic] la ciencia, á [sic] la religión y á [sic] otras cosas en ocasiones de indiscutible importancia; pero es preciso consagrar al arte más atención, más respeto y mirar sus progresos como el fiel reflejo del adelanto de un pueblo.

La Comisión encargada de las reparaciones del Teatro, estando verdaderamente interesada en el bien del país (lo que no dudamos) podrá fácilmente dar al arruinado edificio un aspecto decente, proveerlo de algún adorno, hacerlo menos indigno de la capital de una nación, mientras llega el día en que podamos levantar un templo digno de los esplendores del arte ${ }^{93}$.

Así, este ciudadano ilustrado compartió sus apreciaciones, las cuales reproducen ideas de origen ilustrado, romántico y positivista. Tales ideologías habían sido potenciadas desde las instituciones de educación estatal y algunas asociaciones civiles, principalmente a partir de la década de 1870 (sin olvidar que la UST estuvo activa entre 1843 y 1888), lo cual generó un escenario ideológico donde predominaron el liberalismo, el krausismo español y los positivismos francés y británico ${ }^{94}$. Al ser ideologías gestadas en culturas herederas de la concepción moderna de las Bellas Artes, un paradigma artístico consolidado entre los siglos XVI y XVIII, el liberalismo, el krausismo y el positivismo le conferían a las artes un lugar importante en la sociedad y un indicador de la cultura de un pueblo. Aunado a este trasfondo intelectual, hay que agregar que los ciudadanos que tenían acceso a los manifiestos ideológicos de tales escuelas de pensamiento pertenecían a los mismos sectores sociales que integraban el Club Internacional y los cargos de la República.

En síntesis, varios ciudadanos con ideología liberal-progresista organizaron desde su asociación particular un proyecto tutelado por el Gobierno de la República, el cual pretendía mejorar las condiciones materiales del núcleo del entretenimiento y la sociabilidad del sector social al que pertenecían quienes integraron aquella Junta del Teatro. Entonces, parece que dicho proyecto derivó de la convergencia de motivaciones ideológicas y las necesidades de un sector de consumidores de alta cultura; debe recordarse que el proyecto fue oficializado en el Salón de Recibo del Club Internacional, un claro indicador de lo que acá se propone. Sin embargo, por razones todavía desconocidas, el proyecto nunca se concretó y parece que la Junta del Teatro desapareció hacia 1886.

De modo paralelo al asunto de la Junta del Teatro, el Club Internacional organizó un gran baile en honor a sus cinco años de existencia ${ }^{95}$. Similar al caso de la Junta del Teatro, el Diario de Costa Rica informó a sus lectores de la organización del evento y posteriormente reseñó lo acontecido en el Club Internacional la noche del sábado 22 de agosto $^{96}$. En el número del 25 de agosto del diario josefino, el redactor dedicó al baile las siguientes líneas:

\footnotetext{
${ }^{93}$ Diario de Costa Rica, "Teatro", 19 de junio de 1885, 4.

${ }^{94}$ Santamaría, "Análisis de la conformación", 90-105.

${ }^{95}$ Diario de Costa Rica, "El", 14 de agosto de 1885, 2.

${ }^{96}$ Diario de Costa Rica, "Una gran fiesta", 25 de agosto de 1885, 2.
} 
Todo el brillo del más refinado lujo en los adornos y disposición del local; la suavidad y finura de la más culta sociedad; y el lujo más esplendoroso aun de la naturaleza concentrado en el rostro de las bellísimas reinas de la fiesta, en esos semblantes que una vez vistos jamás se borran de la memoria y del corazón; en todo lo que de precioso encanto encierra una mujer hermosa, el mayor lujo de la naturaleza y su más admirable creación [...].

Todas las bellezas del arte, toda la magnificencia de lujo superior; todas las gracias y primores de las mujeres bellas, todo, en fin lo que puede por un momento hacer de la tierra un Eden [sic] trayendo al alma sueños embriagadores y al corazon [sic] expansiones de felicidad, estaba combinado felizmente en el salón del Club en la inolvidable noche del sábado.

A las seis de la mañana del domingo, sin que en toda esa noche brillante hubiera ocurrido ni el más leve incidente desagradable, regresaban á [sic] su casa los invitados llevando dulces impresiones de felicidad, y justa admiración y gratitud hacia los dignos miembros del Club que tan preciosas horas de solaz les brindaron con su magnificencia y cultura $^{97}$.

En términos generales, el redactor estableció una clara relación entre el Club Internacional y el progreso cultural del país, o sea, destacó la gestión cultural de los miembros del club encargados de tales eventos. De entrada el escritor calificó a los invitados al baile como la "más culta sociedad", la cual estaba integrada por caballeros ilustres y "mujeres bellas". Igual al caso de la crónica publicada por motivo del baile celebrado por el Club Nacional en 1876, la reseña periodística del baile del Club Internacional destaca la presencia de mujeres, principalmente por su belleza.

Como ya se ha advertido, la "más culta sociedad" josefina aspiraba a emular las dinámicas sociales de la aristocracia y la gran burguesía europea. Una muestra de tal actitud es la reproducción de un artículo titulado "La apoteosis de los animales. Un baile en el gran mundo", aparecido en el número del Diario de Costa Rica del 25 de agosto (misma edición en que se publicó la crónica del baile del Club Internacional arriba citada) y publicado originalmente por el Diario de Centro América, una reconocida publicación guatemalteca de la época ${ }^{98}$. Dicho texto corresponde a una reseña de un baile de disfraces acontecido en París a expensas de la princesa de Sagan, al cual acudió "toda la sociedad aristocrática de Francia y todas las personas de elevada posición [...] Princesas, duques y duquesas, todo el mundo blasonado, los herederos de los títulos más gloriosos de Francia y muchos del resto de Europa"99. Aunque el articulista tilda esta actividad digna de locos y subraya el carácter irracional de la misma, la crónica se concentra en describir con admiración los disfraces de los asistentes y a resaltar el lujo y exotismo de las actividades de las élites del "gran mundo".

\footnotetext{
${ }^{97}$ Diario de Costa Rica, "Una gran fiesta", 25 de agosto de 1885, 2.

98 Diario de Costa Rica, "La apoteosis de los animales. Un baile en el gran mundo", 25 de agosto de $1885,1-2$.

${ }^{99}$ Diario de Costa Rica, "La apoteosis de los animales", 1.
} 
Tomando en cuenta el interés de estos grupos por la vanguardia europea (culta) en cuanto a prácticas festivas y lo expuesto en el primer capítulo, lo hasta acá desarrollado permite proponer que el Club Internacional era una asociación que promovía un modelo cultural-asociativo inspirado en las sociabilidades europeas modernas e intentó reproducir en Costa Rica las actividades apetecidas en las naciones consideradas cultas y progresistas. Hacia dicha dirección fue proyectada la crónica del baile publicada por La Chirimia el 29 de agosto, en ella el redactor alabó el evento y agregó, en relación con las mujeres asistentes:

No nos singularizamos a pesar de que algunas morenas que no son suavizadas por las brisas del Rhin, sino por los vientos norte y sur que dimanan de Torres y María Aguilar, no dejan de presentarse más seductoras que la fruta del paraíso que dió [sic] en tierra con nuestros primeros padres. De poco espacio disfrutamos para ocuparnos del baile, pero bastenos [...] manifestar que no dejó que desear y que su buena organización dependió del buen gusto de los distinguidos socios del $\mathrm{Club}^{100}$.

Si bien la comparación del Rhin con los ríos Torres y María Aguilar parece haber sido motivada por el humor ${ }^{101}$, es interesante tal relación entre Europa y Costa Rica, entre lo verdadero y su imitación. No se propone acá que las élites josefinas de la década de 1880 pretendieran vivir en una sociedad exactamente igual a la inglesa o francesa; sin embargo, compartían la idea que el modelo sociocultural occidental era el mejor; en consecuencia, muchas de sus prácticas culturales se basaron en lo que hacían los habitantes del "gran mundo".

Tal afán civilizador distinguió al Club Internacional, o al menos así fue caracterizado en una suerte de editorial, relativo al baile del sábado 22 de agosto, que se publicó en el número del Diario de Costa Rica del viernes siguiente ${ }^{102}$. Dicha crónica fue más detallada que las anteriormente comentadas, de modo que revela información valiosa para reconstruir lo acontecido esa noche en el Club Internacional. En conformidad con el articulista, el baile fue de los mejores que se hubiesen presentado hasta entonces en Costa Rica, lo cual no era de extrañar, pues según el redactor el Club Internacional reflejaba la mayor cultura del país, "así en lo intelectual como en buenas maneras"103. El cronista señaló que el "comité del festejo" se lució con el evento y atendió de gran manera a la "numerosa y escogida concurrencia"104. El salón de baile fue construido para la ocasión sobre el jardín de la casa ocupada por el Club Internacional (antigua vivienda del obispo Thiel); de acuerdo con la reseña, el salón estaba ornamentado con banderas, sin embargo no se detalló cuáles banderas.

\footnotetext{
${ }^{100}$ La Chirimia, "Baile del Club", 29 de agosto de 1885, 4.

${ }^{101}$ El Rhin es una importante frontera natural entre varios países de la zona norteña de Europa central y es considerado uno de los principales ríos de ese continente.

${ }^{102}$ Diario de Costa Rica, "Club Internacional", 28 de agosto de 1885, 1-2.

${ }^{103}$ Diario de Costa Rica, "Club Internacional", 1.

${ }^{104}$ Diario de Costa Rica, "Club Internacional", 1.
} 
Con respecto a la música, la velada fue amenizada por una orquesta comandada por el flautista, compositor y director puertorriqueño Mateo Fournier Hetch (1851$1917)^{105}$. Según el relator, el baile fue tan exquisito que las imágenes del festejo "brindaban al observador un cuadro capaz de regocijar á [sic] la misma deidad del arte" ${ }^{\prime 106}$. Al igual que en las otras crónicas del evento, el autor del Diario de Costa Rica dedicó una sección de su comentario a describir a las mujeres que atendieron a la selecta convocatoria:

En este baile estaban todas encantadoras, realzando su belleza natural la elegancia con que iban ataviadas. Las casadas lucían casi todas traje negro y las solteras vestidos multicolores, desde el blanco puro al encarnado subido. En cuanto á [sic] tipos de corrección clásica había algunos dignos de un pincel de primera fuerza; pero entre las más favorecidas llamó la atención un cuerpo de contorno escultórico, regularmente alto, transparente color blanqui-rubio [sic], ojos un tanto azules, busto de proporción geométrica, resultando del conjunto un modelo de arte, capaz de ocultar una alma cincelada por los rayos del sol intertropical, pero suavizados por la frescura de las brisas del Rhin ${ }^{107}$.

Según dicha descripción, el modelo de belleza idealizado corresponde con las características físicas de habitantes de países de otras latitudes del planeta; nuevamente, se estableció una comparación entre el trópico centroamericano y la frescura del río Rhin (quizás en alusión a la ascendencia europea de la mujer descrita). Además, el texto acá citado ofrece una interesante descripción de las maneras de vestir de las mujeres según su estado civil, lo cual permite hipotetizar que quizás tales bailes funcionaban para "presentar en sociedad" a señoritas e incluso para fomentar el emparejamiento entre los miembros de los estratos sociales que participaban de tales encuentros.

\section{Conclusiones}

En correspondencia con lo desarrollado en las páginas que comprenden este trabajo, debe resaltarse como se ha aumentado significativamente el conocimiento relativo al Club Internacional. En este sentido, lo expuesto acá pretende constituir un precedente para ulteriores investigaciones que tengan que estudiar al Club Internacional, a sus miembros o alguno de los proyectos desarrollados durante su primera década de actividad. Debe señalarse que no se considera a este un estudio de carácter especializado sobre el club, por el contrario, en conformidad con las motivaciones de esta investigación, el texto que acá concluye busca introducir al estudio históricocultural del tema tratado.

Con respecto a lo propuesto en este artículo, se concluye que el Club Nacional de 1876 podría ser el antecedente directo del Club Internacional; sin embargo, tal

\footnotetext{
${ }^{105}$ Vargas, De las fanfarrias, 284.

${ }^{106}$ Diario de Costa Rica, "Club Internacional", 1.

${ }^{107}$ Diario de Costa Rica, "Club Internacional", 2.
} 
hipótesis amerita una investigación más profunda para poder someterla a contrastación con fuentes primarias y secundarias. En todo caso, lo cierto es que ambas asociaciones surgieron en el contexto de la crisis de la masonería costarricense y probablemente sendos clubes engrosaron sus filas con masones interesados en participar de una sociabilidad burguesa de carácter comercial y recreativo.

La determinación de los distintos locales del Internacional, el estudio de los estatutos de 1884 y el relato de Magón han permitido ubicar geográfica y socialmente a este importante club josefino. Como se expuso, el Club Internacional se ubicó cerca de puntos urbanos importantes del San José de esa época; además, sus estatutos revelan la naturaleza elitista, liberal-democrática y republicana de la asociación. Por su parte, la comparación de los estatutos del club con los estatutos de la masonería centroamericana, ambos de 1884, posibilitó vincular ambas formas de sociabilidad con un programa intelectual modernizante, liberal y republicano. Dicha comparación también reveló grandes diferencias entre las dos asociaciones, pero estas no representaban un antagonismo ni mucho menos. Por ello, tal y como se evidenció a lo largo del artículo, varias personas participaron de la masonería y a la vez fueron miembros del Club Internacional.

Relativo al Salón del Arte del Club Internacional y considerando los miembros mencionados por Magón, se propone que tal agrupación pudo ser una suerte de club artístico, en el cual convergieron profesionales y aficionados a las Bellas Artes. Ahora bien, dado que en el Salón del Arte hubo conciertos íntimos, declamación de poesía y discusiones teóricas sobre arquitectura, filosofía y política, surge la inquietud de si en el Club Internacional pudo haber exposiciones de artes plásticas o algún otro género de las Bellas Artes.

Sobre los bailes organizados por el Club Internacional, el papel de la prensa y su relevancia para las élites josefinas de la década de 1880, se concluye que dichos eventos y las notas periodísticas sobre estos fueron fundamentales para el proceso de legitimación social de los miembros de los sectores sociales autodenominados cultos e ilustrados. Otro aspecto a tomar en cuenta es la constancia y la envergadura de las actividades organizadas por el Club Internacional durante los últimos veinte años del siglo. Sin duda un análisis cuantitativo de estos eventos podría clarificar el desarrollo de dichas actividades, los índices de asistencia a las mismas, los invitados recurrentes y las agrupaciones de músicos, los cocineros, los hoteleros y los empresarios que se vieron beneficiados por participar en la producción de estos festines burgueses.

Además, considerando el interés del Club Internacional por la Junta del Teatro (1885) y la posible influencia de dicha asociación en las obras para la restauración del Teatro Municipal, llama la atención que los planos originales del Teatro Nacional de Costa Rica (1890) hayan sido modificados durante el proceso de construcción (18911897), ampliando las dimensiones del salón foyer e instalando bajo la platea un sistema de levantamiento que permite unificar el escenario y obtener un gran salón de baile ${ }^{108}$.

${ }^{108}$ Santamaría, "Análisis de la conformación”. 
Ambas reformas fueron realizadas para dotar al Teatro Nacional de espacios adecuados para celebrar bailes y elegantes banquetes, lo cual certifica la importancia que tenían los eventos de gala para la "culta sociedad" de la década de 1890. Tal deducción es respaldada por la reseña histórica del Club Internacional que publicó La Nueva Prensa en 1928, donde se afirma:

Fue en sus salones [del Club Internacional] en donde se efectuaron las recepciones oficiales para los Ministros Extranjeros y en donde se dió [sic] cita la más encumbrada aristocracia josefina.

Largo sería enumerar las fiestas que ahí se han dado, antes de tener el salón del Teatro Nacional, fue en los salones del Club Internacional en donde se reunía para los bailes del 31 de Diciembre, 14 de Diciembre, y demás fechas de importancia para la celebración ellas ${ }^{109}$.

Entonces, parece que el Club Internacional, junto al Palacio Nacional, el Palacio Presidencial y los salones de los hoteles Francés, Internacional e Italia, fue uno de los puntos donde las élites josefinas de las décadas de 1880 y 1890 celebraron sus ostentosos eventos privados.

En relación con los espacios legitimadores procurados por las élites y la participación de la prensa en este proceso de consagración social, se intuye que el Club Internacional sólo fue parte de una red de personas e instituciones (públicas y privadas) que, articuladas por miembros de los sectores sociales más altos, eran vehículo para desarrollar la agenda de estos ciudadanos. Así, la figura de Joaquín Bernardo Calvo es representativa de lo que acá se propone, pues este abogado estuvo vinculado con el Club Nacional, el Club Internacional, la logia Unión Fraternal no. $19^{110}$, el Diario de Costa Rica, la Junta del Teatro y el Gobierno de la República. De modo que en ocasiones Calvo trabajó de manera multidireccional, por ejemplo, siendo miembro del Club Internacional integró la Junta del Teatro, de la cual fue secretario, y a su vez publicitó tal iniciativa en su empresa, el Diario de Costa Rica; dos años después, ahora como funcionario de Gobierno, Calvo publicó un texto histórico oficial, en el cual legitimó el gobierno de Bernardo Soto y de paso calificó al Club Internacional como "el establecimiento recreativo más respetable del país"111.

Finalmente, se propone que mediante el estudio sistemático del Club Internacional y de las actividades sociales y artístico-culturales producidas por el mismo, la Historia del Arte y la Historia de la Cultura costarricense encontrarán en esta asociación un importante núcleo de la cultura ilustrada, la cual rigió las prácticas socioculturales de las élites costarricenses durante las décadas de 1880 y 1890. Con esto no se sugiere que el período de actividad del Club Internacional se haya limitado a las

\footnotetext{
${ }^{109}$ La Nueva Prensa, "Inauguración del Nuevo Edificio del Club Internacional", 29 de diciembre de $1928,15$.

${ }^{110}$ Joaquín Bernardo Calvo Mora participó de la masonería costarricense entre los años 1883 y 1887. Martínez, Masones y masonería, 104.

${ }^{111}$ Calvo, Apuntamientos geográficos, estadísticos é históricos, 178.
} 
últimas dos décadas del siglo XIX, pues se sabe que el club seguía activo hacia finales de la década de 1920; sin embargo, debe tenerse claro que en los primeros decenios del siglo XX surgió en Costa Rica un sinnúmero de asociaciones civiles, las cuales diversificaron el escenario asociativo costarricense y le restaron protagonismo al Internacional. Por supuesto, este último tema se sale de los límites de este trabajo y se expone acá como uno de los tantos caminos por recorrer en la investigación histórica sobre el Club Internacional de San José.

\section{Fuentes primarias}

\section{Hemeroteca de la Biblioteca Nacional}

Diario de Costa Rica 1885.

El Costarricense 1874, 1876.

Gaceta Oficial 1876, 1885.

La Chirimia 1885.

La Prensa Libre 1892.

Nueva Era 1861.

\section{Impresas}

Calvo, Joaquín Bernardo. Apuntamientos geográficos, estadísticos é históricos. San José: Imprenta Nacional, 1887.

Club Internacional de Costa Rica. Estatutos del Club Internacional de Costa Rica. San José: Gran Imprenta á Vapor - Cenedella \& Greñas, 1897.

Club Internacional. Estatutos del Club Internacional. San José: Imprenta Nacional, 1884.

Fernández Guardia, Ricardo, ed. Costa Rica en el siglo XIX: antología de viajeros. San José: EUNED, 2002.

González Zeledón, Manuel. Cuentos de Magón. San José: Imprenta Nacional, 2012.

\section{Bibliografía}

Arias Castro, Tomás Federico. "El delito de duelo en Costa Rica (Análisis históricojurídico)". Revista Judicial, no. 101 (septiembre 2011), http://sitios.poderjudicial.go.cr/escuelajudicial/documentos/revs_juds/revista $\% 20101 /$ pdf/08_delit oduelo.pdf

Beaurepaire, Pierre-Yves. "Sociabilidad y Francmasonería. Propuestas para una historia de las prácticas sociales y culturales en el Siglo de la Luces". En 300 años: Masonerías y Masones (1717-2017). Tomo V. Cosmopolitismo. Editado por Ricardo Martínez Esquivel, Yván Pozuelo Andrés y Rogelio Aragón. Ciudad de México: Editorial Palabra de Clío, 2018.

Blen, Adolfo. Historia del periodismo. San José: Editorial Costa Rica, 1983. 
Bourdieu, Pierre. El sentido social del gusto. Elementos para una sociología de la cultura. Buenos Aires: Siglo Veintiuno Editores, 2010.

Fallas Santana, Carmen María. Elite, negocios y política en Costa Rica: 1849-1859. Alajuela: Museo Histórico Juan Santamaría, 2004.

Fumero Vargas, Patricia. Teatro, público y estado en San José 1880-1914. San José: Editorial de la Universidad de Costa Rica, 1996.

González Bernaldo de Quirós, Pilar. "La 'sociabilidad' y la historia política". Nuevo Mundo Mundos Nuevos (2008). http://journals.openedition.org/nuevomundo/24082

González Bernaldo de Quirós, Pilar. "Sociabilidad y opinión pública en Buenos Aires (1821-1852)”. Historia Contemporánea, no. 27 (2003): 663-694. http://www.ehu.eus/ojs/index.php/HC/article/view/5205

González Bernaldo de Quirós, Pilar. "Literatura injuriosa y opinión pública en Santiago de Chile durante la primera mitad del siglo XIX". Estudios Públicos, no. 76 (1999): 233-262. https://www.cepchile.cl/literatura-injuriosa-y-opinion-publicaen-santiago-de-chile-durante-la/cep/2016-03-03/183845.html

Junta de Andalucía. Rehabilitación edificio La Alhambra. San José, Costa Rica. Andalucía: Consejería de Fomento y Vivienda de la Junta de Andalucía, 2011.

Lander, María Fernanda. "El Manual de urbanidad y buenas maneras de Manuel Antonio Carreño: Reglas para la construcción del ciudadano ideal". Arizona Journal of Hispanic Cultural Studies VI (2002): 83-96. http://www.jstor.org/stable/20641598

Loaiza Cano, Gilberto. "Hombres de sociedades (masonería y sociabilidad políticointelectual en Colombia e Hispanoamérica durante la segunda mitad del siglo XIX)", Revista Historia y Espacio, no. 17 (2001): 93-130. http://hdl.handle.net/10893/7400

Martínez Esquivel, Ricardo. Masones y masonería en la Costa Rica de los albores de la modernidad (1865-1899). San José: EUCR, 2017.

Milne-Smith, Amy. London Clubland: A Cultural History of Gender and Class in Late Victorian Britain. Nueva York: Springer, 2011.

Molina Jiménez, Iván y Steven Palmer eds. Héroes al gusto y libros de moda: sociedad y cambio cultural en Costa Rica 1750-1900. San José: Editorial Porvenir, 2004.

Muñoz Cabrejo, Fanni. "Viejas versus nuevas diversiones: el esfuerzo por modernizar la cultura limeña”. En Las Clases Medias, entre la pretensión y la incertidumbre. Editado por G. Portocarrero. Lima: SUR, Casa de Estudios del Socialismo, OXFAM, 1998.

Obregón Loría, Rafael y George Bowden. La Masonería en Costa Rica. Segundo periodo. San José: Trejos Hermanos, 1938.

Oviedo Salazar, Mauricio y Leonardo Santamaría Montero. "Los Durini: redes de mercado cultural en Centroamérica". Informe final de investigación, Instituto de Investigaciones en Arte, Universidad de Costa Rica, 2016. 
Quesada Monge, Rodrigo. Recuerdos del imperio: los ingleses en América Central (1821-1915). Heredia: EUNA, 1998.

Sala, Céline. "La sociabilidad masónica francesa en la encrucijada de las fronteras fraternales y profanas: el ejemplo de la ciudad de Perpiñán en el siglo XVIII". REHMLAC+ 1, no. 2 (diciembre 2009-abril 2010): 2-16. https://revistas.ucr.ac.cr/index.php/rehmlac/article/view/6614/26722

Salazar Mora, Orlando. El apogeo de la república liberal en Costa Rica: 1870-1914. San José: EUCR, 2003.

Salazar Rodríguez, María Angélica. "De encajes, sedas y moños: una historia del performance burgués y de la distinción social en Bogotá (1886-1899)". Monografía de grado en historia, Universidad Colegio Mayor de Nuestra Señora del Rosario, 2012.

Sanou, Ofelia y Florencia Quesada. "Orden, progreso y civilización (1871-1914). Transformaciones urbanas y arquitectónicas". En Historia de la Arquitectura en Costa Rica. Editado por Elizabeth Fonseca y José Enrique Garnier. San José: Fundación Museos del Banco Central de Costa Rica, 1998.

Santamaría Montero, Leonardo. "Análisis de la conformación del diseño arquitectónico y ornamental del Teatro Nacional de Costa Rica". Tesis de licenciatura en historia del arte, Universidad de Costa Rica, 2017.

Soto-Quirós, Ronald. "La difusión del etnotipo costarricense: los Apuntamientos de J. B. Calvo, del texto educativo a la propaganda internacional". Boletín AFEHC, no. 54 (julio-septiembre 2012): vínculo caído.

Taddei, Antonia. "London Clubs in the Late Nineteenth Century". Discussion Papers in Economic and Social History 28 (1999): 1-26. http://www.nuff.ox.ac.uk/economics/history/paper28/28taddeiweb1.pdf

Vargas Araya, Armando. El doctor Zambrana. San José: EUNED, 2006.

Vargas Cullell, María Clara. De las fanfarrias a las salas de concierto: música en Costa Rica, 1840-1940. San José: EUCR, 2004.

Zeledón Cartín, Elías comp. Del viejo San José. San José: EUCR, 2004. 


\section{Anexo 1 \\ Estatutos del Club Internacional (1884) ${ }^{112}$}

\section{ESTATUTOS DEL CLUB INTERNACIONAL}

\section{TITULO I.}

Del objeto de la asociación.

Art. $1^{\circ}$-El Club Internacional establecido en San José, es una asociación de individuos que, admitidos según las reglas que previenen estos Estatutos, y regiéndose [sic] por ellas, se juntan para su recreo ó [sic] sus negocios, y contribuyen con una cuota fija, destinada para el sostén y desarrollo del establecimiento. Su número es por ahora ilimitado.

\section{TITULO II.}

De la administración y gobierno del Club.

Art. $2^{\circ}$-La administración y gobierno del Club corresponde á [sic] un Directorio, que se compone de un Presidente, un Tesorero, un Secretario y dos Vocales; estos últimos suplen á [sic] quien se ausente de los primeros, y forman parte de la Dirección. Sus funciones duran un año, pudiendo ser reelectos indefinidamente.

Art. $3^{\circ}$-Compete al Directorio:

$1^{\circ}$-La administración gubernativa y económica de todos los negocios concernientes á [sic] la Sociedad, haciendo observar puntualmente lo prescrito por estos Estatutos.

$2^{\circ}$-Formar y variar el Reglamento interior, determinando en él los juegos permitidos ó [sic] prohibidos, y sus límites.

$3^{\circ}$-Convocar á [sic] Junta general cuando lo creyere conveniente, y en especial todos los años para el primer domingo de enero, á [sic] la una del día; con el objeto de elegir el Directorio que deba sucederle, así como también para el cumplimiento de todas y cada una de las funciones que estos Estatutos atribuyen á [sic] la expresada Junta. Deberá, además, hacer igual convocatoria siempre que lo soliciten por escrito, expresando el objeto, á [sic] lo menos diez socios. La convocatoria deberá fijarse en la pizarra del Club, por lo menos ocho días antes del designado para la reunión, y también convocada por medio de circular (véase el art. 11).

${ }^{112}$ Club Internacional, Estatutos del Club Internacional (San José: Imprenta Nacional, 1884). 
$4^{\circ}$-Dar cuenta de su administración, presentando una razón de la [sic] entradas del establecimiento y su inversión, la que pasará á [sic] la comisión revisora de cuentas, para que la presente informada á [sic] la Junta general que se reune [sic] anualmente el primer domingo de enero.

\section{TITULO III.}

De la admisión y exclusión de socios.

Art. $4^{\circ}$-Todos los socios del Club tienen derecho para proponer nuevos socios. En consecuencia, toda persona que desee formar parte de esta asociación, deberán ser propuesta por un socio al Secretario del Club, quien inscribirá la proposición en un libro llevado al efecto, expresando el nombre del proponente y del propuesto, y con ella dará cuenta al Directorio, á [sic] fin de que éste, en su primera sesión ordinaria, determine el día en que debe tener lugar la reunión general para la admisión del presentado. Del acuerdo respectivo se fijará un aviso en la pizarra del establecimiento, ocho días anticipados, suscrito por el Secretario, en que se expresa la propuesta y la citación á [sic] todos los socios. Llegando el día y hora señalados, la Junta general procederá á [sic] decidir en votación secreta, si el propuesto es aceptado ó [sic] rechazado. La votación se hará por medio de fichas ó [sic] bolas blancas y negras, expresando aquellas la aceptación, y éstas, el rechazo. Si, hecho el escrutinio á [sic] presencia del Directorio, resultaren cinco votos por el rechazo, el candidato se tendrá por no propuesto. El resultado de la votación lo comunicará el Secretario al socio proponente.

Art. $5^{\circ}$-El nuevo socio no podrá introducirse al Club sin haber satisfecho previamente la cuota de introducción y el valor de la suscrición [sic] correspondiente al mes en curso.

\section{TITULO IV.}

Del Secretario y Tesorero.

Art. $6^{\circ}$-Las funciones del Secretario se reducen en general á [sic] ejecutar los acuerdos del Directorio.

Art. $7^{\circ}$-Le compete además en particular:

$1^{\circ}$-Hacer cumplir el Reglamento interior del establecimiento.

$2^{\circ}$-Llevar el libro de introducciones y propuestas de socios, y el de acuerdos del Directorio y Junta general.

$3^{\circ}$-Fijar los avisos de citación para la misma Junta y hacer la convocatoria por medio de circular. 
$4^{\circ}$-Llevar un libro en el cual se registre el nombre y nacionalidad de los transeuntes [sic] presentados, así como el de los socios presentantes.

Art. $8^{\circ}$-El Tesorero tendrá el manejo de los fondos y llevará la cuenta de entradas y salidas del establecimiento, presentándola á [sic] la Junta Directiva para que la apruebe ó [sic] la observe.

Art. $9^{\circ}$-Presentará también una cuenta anual del estado de los fondos del Club, la que, informada por la comisión revisora de cuentas, será presentada á [sic] la reunión general, que tendrá lugar cada primer domingo de enero.

TITULO V.

De las Juntas generales.

Art. 10.-El primer domingo del mes de enero de cada año, á [sic] la una del día, habrá una Junta general de socios con el objeto de elegir el Directorio y la comisión revisora de cuentas. La elección se hará por medio de boletas escritas y por mayoría absoluta de votos entre los presentes.

Art. 11.-Para toda Junta general debe citarse por medio de circular y con ocho días de anticipación, á [sic] los socios que residieren en esta capital, quienes firmarán dicha circular en prueba de haber sido notificados. Llenada que sea dicha formalidad el día y hora prefijados, se declarará instalada la Junta, cualquiera que sea el número de los socios presentes, y funcionará dictando las resoluciones del caso por mayoría de votos.

Art. 12.-Solo la Junta general puede variar las cuotas de introducción y suscrición [sic] con que deben contribuir los socios.

\section{TITULO VI.}

De la comisión revisora de cuentas.

Art. 13.-Esta comisión se compondrá de tres socios propietarios, elegidos por mayoría de votos en la Junta general del primer domingo de enero.

Art. 14.-Le corresponde examinar las cuentas anuales que presente el Directorio y Tesorero, y presentarlas á [sic] la Junta general indicada, con un informe que manifieste el juicio que ha formado de ellas.

TITULO VII.

Disposiciones generales. 
Art. 15.-Solo los socios del Club pueden frecuentar el establecimiento; no obstante, se admitirán transeuntes [sic], los cuales no tienen los privilegios de los socios, ni voto en los asuntos del Club.

Art. 16.-Son miembros honorarios, sin voto en las elecciones y deliberaciones del Club, el Presidente de la República y los Secretarios de Estado.

Art. 17.-Todos los agentes de la carrera diplomática tendrán derecho de ser presentados al Club por algún socio, y continuar por el tiempo que quieran, pagando la cuota mensual establecida.

Art. 18.-Los transeuntes [sic] son las personas que, no teniendo su residencia en la provincia de San José, fueren presentados al Club por algún socio. Se entenderán residentes en la provincia, y no podrán ser introducidos con tal carácter, aquellos cuya familia residiere en la capital. El transeunte [sic], una vez presentado, si llena los requisitos, recibirá una boleta de entrada firmada por el Secretario, que llevará el nombre del introductor y del transeunte [sic], y en que se expresará que puede frecuentar el Club por el término de treinta días, sin pagar cosa alguna, y que en caso de querer continuar, podrá hacerlo sin inconveniente por todo el tiempo que dure su residencia en la capital, pagando las cuotas correspondientes á [sic] los demás meses.

Art. 19.-La cuota de introducción que deben satisfacer los nuevos socios propietarios, queda fijada en treinta pesos.

Art. 20.- La cuota de introducción de los socios asistentes queda fijada en diez pesos. Los socios fundadores, propietarios ó [sic] asistentes, pagarán una cuota mensual de $\$$ $2-50$.

Art. 21.-Los socios asistentes pueden hacerse socios propietarios en cualquier tiempo, pagando la diferencia entre treinta y diez pesos. Los socios asistentes gozarán de los mismos derechos de los socios transeuntes [sic], sin tener voto ni propiedad en el Club.

Art. 22.-Los socios deberán pagar sus cuotas al establecimiento cada primero de mes, y la falta de pago de éstas por dos meses consecutivos será suficiente causa para que el socio moroso quede de hecho excluido de la sociedad, reservándole sin embargo el derecho de reclamar á [sic] la Dirección en caso de injusticia, dentro de quince días de haber sido notificado.

Art. 23.-Todo nuevo socio que al incorporarse no pague la cuota de introducción, dejará de hecho de pertenecer al Club. El socio que no se incorpore un mes después de 
notificada su admisión, se tendrá por no presentado. Se entiende incorporado el que después de admitido satisface la cuota de introducción.

Art. 24.-El socio que desee retirarse debe dar aviso por escrito al Secretario. Si así no lo hiciera quedará obligado al pago de las mensualidades por ahora establecidas y á [sic] las que en adelante se establecieren.

Art. 25.-Los socios que por cualquiera causa se ausenten del país por cinco meses ó [sic] más, pueden eximirse de pagar su cotización durante este tiempo, pasando previo aviso de su ausencia al Secretario del Club. Si á [sic] su vuelta quieren continuar como socios, pagarán por la reincorporación el importe de dos mensualidades de la cuota designada á [sic] cada socio. Los socios residentes en el país pagarán las mensualidades, ausentes ó [sic] no de la capital.

Art. 26.-Siendo el Club de carácter internacional, se prohíbe la discusión de cuestiones políticas de toda clase, sea de este país ó [sic] extranjero, que puedan ser ofensivas á [sic] cualquier socio.

Art. 27.-No se podrán modificar ó [sic] reformar estos Estatutos ni dictarse otros nuevos, sin la aprobación de las dos terceras partes de los socios reunidos en Junta general para este objeto, y sin la confirmación de la mayoría de una segunda Junta, que tendrá lugar por lo menos ocho días después, para acordar y sancionar lo que se hubiere resuelto en la anterior.

Art. 28.-Los presentes Estatutos comenzarán á [sic] regir desde la fecha de su aprobación.

Dados en San José, el día veintisiete de enero de mil ochocientos ochenta y cuatro.

C. R. LORDLY. PRESIDENTE

CAMILO MORA A. SECRETARIO.
A. VANSITTART. TESORERO

MANUEL CARAZO. VOCAL.

Aprobados en Asamblea general el día 10 de febrero de 1884.

Camilo Mora. A.

Secretario. 